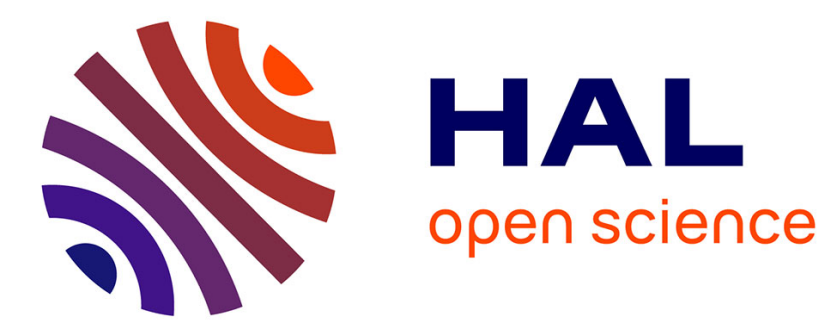

\title{
Flameless venting of dust explosion: Testing and modeling
}

Yann Grégoire, Emmanuel Leprette, Christophe Proust

\section{To cite this version:}

Yann Grégoire, Emmanuel Leprette, Christophe Proust. Flameless venting of dust explosion: Testing and modeling. Journal of Loss Prevention in the Process Industries, 2021, 73, pp.104596. 10.1016/j.jlp.2021.104596 . ineris-03356805

\section{HAL Id: ineris-03356805 \\ https://hal-ineris.archives-ouvertes.fr/ineris-03356805}

Submitted on 3 Feb 2022

HAL is a multi-disciplinary open access archive for the deposit and dissemination of scientific research documents, whether they are published or not. The documents may come from teaching and research institutions in France or abroad, or from public or private research centers.
L'archive ouverte pluridisciplinaire HAL, est destinée au dépôt et à la diffusion de documents scientifiques de niveau recherche, publiés ou non, émanant des établissements d'enseignement et de recherche français ou étrangers, des laboratoires publics ou privés. 


\title{
Flameless venting of dust explosion: testing and modeling
}

\author{
Yann Grégoire $^{a}$, Emmanuel Leprette $^{a}$ \& Christophe Proust ${ }^{a, b}$ \\ E-mail: yann.gregoire@ineris.fr \\ ${ }^{a}$ Institut National de l'Environnement Industriel et des Risques, PARC ALATA, BP2, \\ Verneuil-en-Halatte, 60550, France \\ ${ }^{b}$ Sorbonne Universities, Technological Univ. of Compiègne, ESCOM, TIMR Centre Pierre \\ Guillaumat, Compiègne, 60200, France
}

\begin{abstract}
Flameless venting is a sort of dual mitigation technique allowing, in principle, to vent a process vessel inside a building where people are working without transmitting a flame outside the protected vessel. Existing devices are an assembly of a vent panel and a metal filter so that the exploding cloud and the flame front is forced to go through the filter. Within the frame of ATEX Directive, those systems need to be certified. To do so a standard (NF EN 16009) has been issued describing which criteria need to be verified / measured. Among them, the "efficiency" factor as defined earlier for standard vents. This implies that flameless venting systems are basically considered as vents. But is it really so? This question is discussed on the basis of experimental results and some implications on the practical use and certification process are drawn. The practical experience of INERIS in testing such systems is presented in this paper. Schematically, with a flameless vent the pressure is discharged but not the flame so that combustion is proceeding to a much longer extent inside the vessel than with a classical vent so that the physics of the explosion is different. In particular it is shown that besides the problem of the unloading of the confined explosion, there is a highly complicated fluid mechanics problem of a fluid-particle flow passing through a porous media (the flameless device grids arrangement in the filter), which passing surface is progressively reduced. To characterize Flameless venting the problem can be addressed sequentially, considering separately the vent panel and the flameless mesh. A model is proposed to estimate the overall venting efficiency of the flameless vent. However, it does not address the flame quenching issue, which is a different problem of heat exchange between the devices and the evacuated burnt products.
\end{abstract}

Keywords: dust explosions, vented explosions, flameless venting, explosion mitigation

\section{Introduction}

Over the last decades, a significant number of experimental studies demonstrated that the dust explosion venting technique can be applied to a wide range of industrial situations and that it is 
possible to establish reasonable dimensioning rules to estimate the required vent areas. A number of guidelines or standards were developed to help the designers in France (AFNOR), in the USA (NFPA), in United Kingdom (BSI), in Germany (VDI). It was observed that the results provided by these methods differed significantly [1]. In an effort to harmonize the practices and to cover more situations additional work was performed during the last ten years which resulted in upgraded versions of VDI3673 [2], EN14491 [3] and NFPA68 [4] documents which tend to become international references. In parallel since the last decade of the twentieth century a specific venting technology emerged to comply with the need of indoor installations: flameless venting. This is a sort of dual mitigation technique allowing, in principle, to vent a process vessel inside a building where people are working without transmitting a flame outside the protected vessel. Existing devices are an assembly of a vent panel and a metal filter so that the exploding cloud is forced to go through the filter. Within the frame of ATEX Directive, those systems need to be certified. To do so a standard (EN16009 [5]) was issued describing which criteria need to be verified / measured. Among them, the "efficiency" factor as defined earlier for standard vents: it is the ratio between the effective venting area and the physical vent area. It is stated in EN16009 that the flameless device efficiency can be influenced not only by the burning properties of the combustible mixture, but also by the physical properties of the dusts (coarse, fibrous, melting and any other parameters that may lead to the device blockage) or by overheating. Nonetheless, the standard does not consider any differences between the efficiency of a standard vent panel of the efficiency of a flameless system:

This implies that flameless venting systems are implicitly considered as functioning like vents. But is it really so? With a flameless vent, the pressure is discharged but not the flame so that combustion is proceeding to a much longer extent inside the vessel than with a classical vent. Consequently, the physics of the explosion is different. The purpose of the present work is to analyze the behavior of flameless venting with respect to venting efficiency, bearing in mind the above considerations. In the following, available data from the literature is recalled but additional data are presented. A discussion follows from which a model based on experimental observation is derived.

\section{State of the art}

\subsection{Dust explosion venting fundamentals}

A vent panel is usually a metal sheet placed on the wall of a vessel, designed to open at a chosen pressure (usually close to $100 \mathrm{mbar}$ ) in the event of an explosion inside this enclosure. It aims at discharging the excess of burnt gases due to the explosion and limit the maximum overpressure to a reduced value often designated $\mathrm{P}_{\text {red. }}$ This passive mitigation system is of low cost and is widely used in the industry. Besides this functioning principle, it is interesting to look closer at the physics at stake during explosion venting. Consider an isolated and partially confined enclosure in which a dust cloud is formed then ignited. An enclosure with a uniform pressure is assumed, which may not be the case as soon as the length over diameter ratio is larger than 5 [6]. The pressure rise is directly linked to the quantity of gases produced by the 
combustion minus the gases lost by the various openings on the enclosure: a vent panel in the present case. The pressure rise versus time curve can be estimated with a model such as [7]:

$$
\frac{1}{P} \frac{d P}{d t}=\gamma \cdot \frac{Q_{\text {produced }}-Q_{\text {lost }}}{V}
$$

where $\mathrm{P}, \mathrm{V}$ and $\gamma$ are the enclosure pressure, volume and the specific heat ratio of the gaseous species. Qproduced and Qlost are respectively the volumetric fluxes produced by the combustion and lost through the vent. At the beginning of the explosion, the Qlost term is null as the vents are closed. Consequently, the pressure rise is entirely governed by the produced gases flux Qproduced. It depends both on the products that are reacting but also on their environment which will influence the flame surface or impose concentration or turbulence gradients. Gas production through combustion can be approximated with this simple model: a zero-thickness flame surface Af, grows spherically at a velocity St in the vessel transforming instantaneously the fresh combustible mixture in hot burnt products that expand of a ratio $\alpha$ :

$$
Q_{\text {produced }}=S t . \text { Af. }(\propto-1)
$$

The expansion ratio $\alpha$ is a thermodynamic data which depends on the heat released by the combustion, linked to the combustible mixture composition. Generally, in the process industries it is comprised between 6 and 8 [8]. The determination of Af and St is more complex as both are strongly influenced by the fluid flow (its turbulence) in the vessel. In industrial applications, it is more convenient to rely of on the empirical definition of $\mathrm{K}_{\mathrm{St}}$ :

$$
K_{S t}=\left(\frac{d P}{d t}\right)_{\max } \cdot V^{1 / 3}
$$

Replacing this in equation (1) (and still assuming no openings on the vessel), we obtain:

$$
K_{S t}=\gamma \cdot k \cdot P_{\text {max }} \cdot \frac{Q_{\text {produced,max }}}{V^{2 / 3}}=\text { constant }
$$

with $\mathrm{k}$ a constant between 0 and 1 .

Later, the vent panels start opening and a part of the gases is discharged in the surroundings of the enclosure. The $\mathrm{Q}_{\text {lost }}$ term is not null and can be estimated from Bernoulli's laws. Better models exist but that presented in equation 5 is acceptable to describe the dominant trends:

$$
Q_{\text {lost }}=C_{d} \cdot A \cdot \sqrt{\frac{\Delta P}{\rho}}
$$

with $\mathrm{Cd}$ a discharge coefficient of the opening, $\mathrm{A}$ the open area, $\Delta \mathrm{P}$ the pressure difference between the vessel, and $\rho$ the density of the fluid. At equilibrium $\Delta \mathrm{P}$ is the reduced explosion pressure Pred, and the equality between the maximum produced and lost gases, leads to a simplification of equation 1:

$$
A \approx \frac{C_{d} \cdot V^{2 / 3}}{k \cdot \gamma \cdot P_{\max }} \cdot \sqrt{\frac{\rho}{P_{\text {red }}}} \cdot K_{S t}
$$

Even in the simplest case of an isolated enclosure with a single vent, the effects of a dust explosion are strongly influenced not only by the nature of the reactants and the initial 
specificities of their environment (geometry, turbulence), but also on the changes in the fluid flow during the explosion. In equation 6 , several terms $\left(\mathrm{K}_{\mathrm{St}}, \mathrm{P}_{\max }, \mathrm{P}_{\mathrm{red}}, \mathrm{V}\right)$ appear in the formulas given in the standards for vent dimensioning (further detailed in the next paragraph). Simulations of such explosion may be performed with an acceptable degree of accuracy using phenomenological tools based on an integral implementation of physical models presented in this section. One can mention for example the EFFEX code from INERIS (see [9] or [10]) or the ISOVEX code form FM Global ([11], [12]) that relies on other models for spherical flames expansions in an enclosure. However, their use is limited to specialists of the explosion field and are hardly accessible to end users in the process industries, that need to implement venting mitigation on real applications.

\section{$2.2 \quad$ Vent dimensioning}

From the preceding analysis, only a few parameters of the explosion scenario need to be known. Dimensioning methods are presented in standards such as EN14491 [3] or NFPA68 [4]. In the example of EN14491, it is necessary to know the maximum pressure allowed in the enclosure $\mathrm{P}_{\text {red }}$, its volume $\mathrm{V}$, its length over diameter ratio $\mathrm{L} / \mathrm{D}$, the reactivity parameters of the dust $\left(\mathrm{P}_{\max }\right.$ and $\mathrm{K}_{\mathrm{St}}$ ) and $\mathrm{P}_{\text {stat }}$ the static opening pressure of the vent panels ( $\geq 0.1$ bar). Empirical correlations were issued: equations 7,8 and 9 , for the calculation of needed vent area $\mathrm{A}_{0}$ for a given application:

$$
\begin{gathered}
A_{0}=B \cdot\left(1+C \cdot \log \left(\frac{L}{D}\right)\right) \\
B=\left[3,264 \cdot 10^{-5} \cdot P_{\text {max }} \cdot K_{S t} \cdot p_{\text {red }}^{-0,569}+0,27 \cdot\left(P_{\text {stat }}-0,1\right) \cdot p_{\text {red }}^{-0,5}\right] \cdot V^{0,753} \\
\text { if } P_{\text {red }}>1.5 \text { bar then } C=-4,305 \cdot \log \left(p_{\text {red }}\right)+0,758 \text { else } C=0
\end{gathered}
$$

These formulas are usable under specific conditions among which a limit in the values of $\mathrm{P}_{\text {red }}$ (0.1 to 2 bar), $\mathrm{K}_{\mathrm{St}}$ (10 to 800 bar.m/s) and $\mathrm{P}_{\max }$ (5 to 12 bar). The "C $\mathrm{C}$ " term in equation 9 accounts for an acoustic flame folding factor [13]. The value of $\mathrm{A}_{0}$ corresponds to a minimum surface to open during the explosion to guarantee that the overpressure will remain below the Pred value. These equations are based on empirical correlations and constitute a significant simplification of the physical models presented in the previous section. However, one can still notice the physics behind the models: the $\mathrm{P}_{\text {red }}$ term is the maximum explosion overpressure, which is reached, according to equation 1 , when $\mathrm{dP} / \mathrm{dt}=0$, meaning that $\mathrm{Q}_{\text {produced }} / \mathrm{Q}_{\text {lost }}=1$. The square root of $\mathrm{P}_{\text {red }}$ on a denominator represents the gases being discharged outside the vessel following equation 5 or 6 , while the $K_{S t} \cdot V^{0.753} \approx K_{S t} \cdot V^{2 / 3}$ is roughly equivalent to the gas production term in equation 4 . In a nutshell, the model describes a competition between the hot gases production and the gases discharge through the vent.

\subsection{Venting efficiency}

Once the necessary vent area $\mathrm{A}_{0}$ is known, the mitigation solution must be implemented. This $A_{0}$ value corresponds to an ideal configuration of an instantly opening, inertia-less vent (surface 
mass inferior to $0.5 \mathrm{~kg} / \mathrm{m}^{2}$ [3]), that oppose no significant resistance to the gas flow. In practice, the vent panel is not ideal and opens progressively, hindering the gas flow. At this stage, the user will look for a vent panel producer or reseller that will inform him on his vent panels efficiency E. This efficiency parameter E may also vary depending on the chosen vent panels and the specificities of the application. Its value indicates a percentage that is used as a corrective parameter increasing the final vent area. The venting efficiency underlines the fact that a vent panel may slow down the gas discharge because of its inertia, in comparison to an instantaneously opened area.

In the standard EN14797 [14], an experimental procedure to measure a vent efficiency is detailed. It consists in testing firstly an inertia-less vent panel, with a specific mass lower than $0.5 \mathrm{~kg} / \mathrm{m}^{2}$, which efficiency is $100 \%$ by definition, then use equations from EN14491 (equations 7 to 9 ) to estimate the dust reactivity parameters product: $\mathrm{P}_{\max } * \mathrm{~K}_{\mathrm{St}}$, the other parameters being either know $\left(\mathrm{A}_{0}, \mathrm{~V}, \mathrm{~L}, \mathrm{D}\right)$ either measured $\left(\mathrm{P}_{\mathrm{red}}\right)$. These data are used to build the characteristic venting curve shown in Figure 1. Alternatively, the same curve can be built from direct fitting on experimental points, provided that several inertia-less vents of different areas can be tested. Secondly the vent panel must be tested in the same conditions, and the same equations are used to estimate a new vent area $A_{1} \leq A_{0}$. The efficiency of the vent panel is the ratio $A_{1} / A_{0}$. A graphical representation is useful to understand how the inertial effect of the panel can be linked to the vent area:

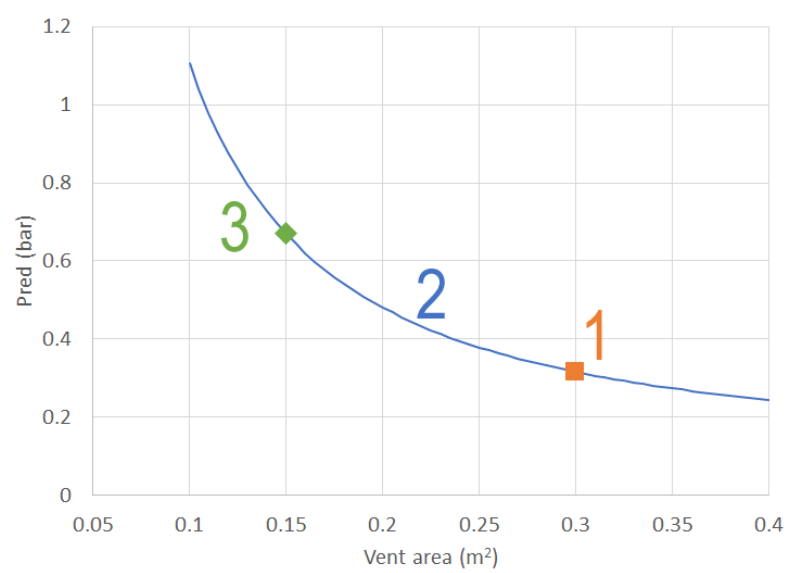

Figure 1 Determination of vent efficiency. Step 1: an inertia-less vent panel is tested, $P_{\text {red }}$ is measured (orange square). Step 2: from this result, the vessel and vent dimensions, (or when testing several vent areas with inertia-less vent panels), the characteristic venting curve (solid blue line) is built. Step 3 a test is performed with a vent panel of unknown efficiency. The measured $P_{\text {red }}$ is reported in the equations (or on the fitted curve, the green diamond here) and a corresponding reduced vent area Al is found. The efficiency of the vent panel is the ratio $A_{1} / A_{0}$.

\section{$2.4 \quad$ Functioning of flameless venting devices}

The earliest Flameless vent device was seemingly prepared by Alfert and Fuhre in 1989 [15]. The system is designated as a "Quenching tube", developed in cooperation with a manufacturer: Rembe Gmbh. Eckhoff [8] describes it as a burst disk connected to tube which walls are "designed to yield a low-pressure drop but high retention efficiency for dust particles and efficient cooling of combustion gases". 
More recently (2006), Holbrow [16] performed an inventory work on the flameless venting devices available on the European market. Most flameless venting devices (Figure 2) are made of an explosion venting device (M), an expansion chamber (C) and a flame quenching / dust retaining element, which will be referred in the following as a "dust explosion filter" (F). The latter is usually a superposition of different metal meshes. From our experience, dust explosion filters include metallic or textile particle retention screens consisting in thin porous layers with holes of diameters on the order of $50 \mu \mathrm{m}$. The other (and coarser) meshes aim at cooling the hot gas-particle flow, they may have mesh sizes on the order of the millimeter. The role of the expansion chamber is to allow a total and free opening of the venting device but also to provide enough area for the "dust explosion filter". The venting device is very often a standard explosion panel, but it may also be a bursting disc, or a spring-loaded valve. The following seem more frequent (Figure 2):

- In the disc type of design (DSQ), the venting device is often a circular spring-loaded valve mounted against the strong top flange. Consequently, the dust cloud and flame can only be vented radially through the "dust explosion filter" and the aspect ratio of the device is smaller than 1 .

- With the cylindrical design (CYL), the venting device is a bursting disc covered with a cylindrical expansion chamber which aspect ratio (L/D) is larger than one. The wall of the expansion chamber is the "dust explosion filter";

- In the box type of arrangement (BOX), the venting device is a vent panel covered with a prismatic expansion chamber. The dust explosion filter usually occupies the largest side of the expansion chamber: in the present schematic, it is open from 0 to $90^{\circ}$ in front of the vent, but we also tested devices with an opening angle up to $135^{\circ}$;
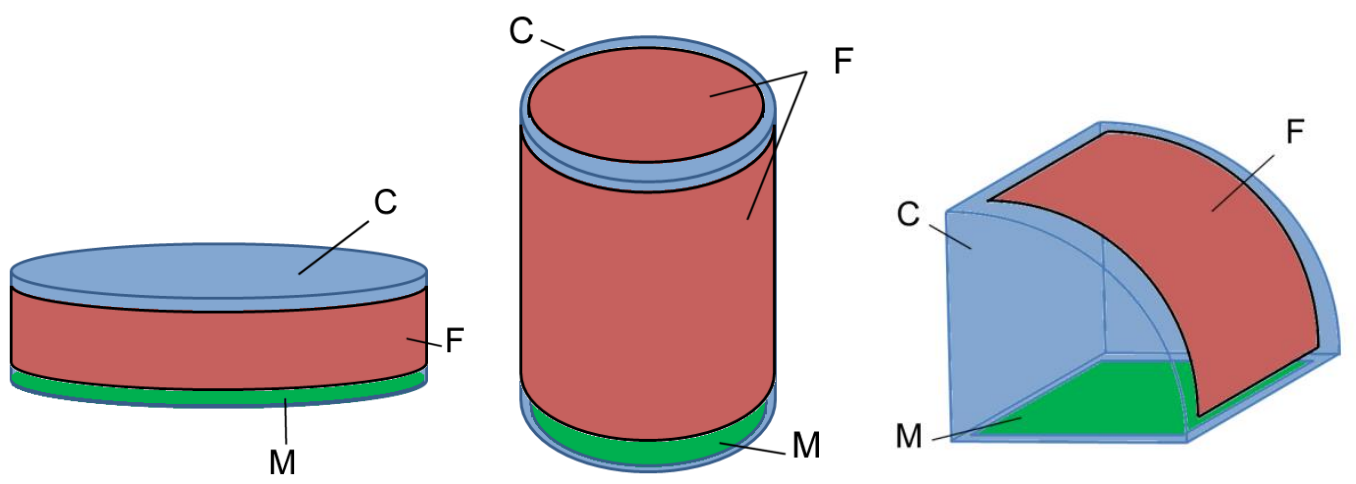

Figure 2 Three principal types of flameless vents. From left to right: disc, cylinder and box type flameless (M: venting device; $C$ : chamber; F: filter)

During the dust explosion, the venting device opens. First the unburnt cloud, later the burnt products, enters the expansion chamber and is pushed through the dust explosion filter. A very large number of particles is trapped, and the flame/burnt products are cooled down by the metal meshes. According to Barton [17], this second mechanism is important because when the burning mixture temperature drops below the minimal ignition temperature of the dust, subsequent flame propagation outside is impeded. In practice however, the device filter may include a particle retention screen. In such case, the dust cloud flowing out from the dust 
explosion filter is very faint, may be too lean to burn anyway so that the first mechanism is certainly as important. So, any flameless device is a series of two consecutive barriers: the venting device and the dust explosion filter acting very differently on the explosion (the first one on the pressure and the second one on the flame).

Nevertheless, in the NFPA68 and EN16009 standards, the flameless device is considered as a standard venting device with some additional limitations (as compared to standard vent panels). These limitations include the impossibility to use the flameless technology for applications involving toxic materials or fibrous / melting dusts (if not duly tested). Further, the flameless venting system is said to have a lower efficiency as compared to the venting device alone and need to be measured. This second limitation is obvious because of expected additional head losses in the dust explosion filter and the first one too because flameless devices are intended to be used indoor. Coarse, fibrous or melting dusts are expected to clog easily the meshes which should render erratic the venting capability of the flameless device. An example was reported by Holbrow [16] about a sugar dust explosion that occurred in 2004 in a bucket elevator at the Sugar Australia Glebe Island Terminal in Australia. Despite the relatively low Kst of the dust (133 bar.m/s, measured in a laboratory) and a venting area judged adequate, it was found out the flameless dust explosion filter located at the bottom of the elevator was clogged and the venting capability was severely impaired.

\subsection{Flameless vents efficiency from the literature}

First, some scientific data is available directly of the manufacturers' websites. STUVEX [18] provides datasheets for a disc type flameless device (“ $D S Q$ ”) and a cylindrical one, ("INDOORVENT"). DSQ system shows efficiencies between 55 and $67 \%$, increasing with the

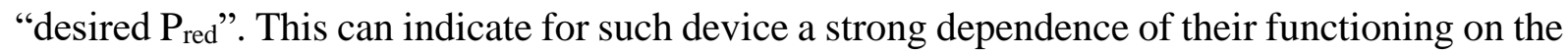
flow conditions. INDOORVENT systems show efficiencies between 76 and $85 \%$, varying (not regularly) with the device diameter, thus underlining the complexity of the interaction of such system with the explosion. IEP technologies [19] provides datasheets about a cylinder type and a box type of flameless venting device. The efficiencies range between 83 and $93 \%$ for the cylinder type, and 59 to $64 \%$ for the box type despite having similar hydraulic diameters. Assuming the filter technologies could be similar between those two devices, this would suggest that a better efficiency is obtained with the cylinder type flameless than with the box type, which could be explained by the larger "dust explosion filter" area for the cylindrical design.

In 1994, Bartknecht and Vogl [20] investigated flameless pressure relief of dust explosions using a bursting disc (static opening overpressure $\mathrm{P}_{\text {stat }}=0,1$ bar) and ribbon type dust explosion filter. As described in EN16009, ribbon type quenching elements are made of alternating layers of thin, corrugated metal ribbons and flat metal ribbons of the same width, which are wound together on a mandrel to form a many-layered cylinder of the desired diameter. Tests were performed with a $1 \mathrm{~m}^{3}$ and with a $60 \mathrm{~m}^{3}$ vessel. It is not clear which dusts were used but it was reported that the device was successful up to a reduced explosion pressure $\left(\mathrm{P}_{\text {red }}\right)$ of 3 bar. Above that value, the barrier effect dropped. In any case, they observed, as it would be expected, that 
the flame arrestor elements caused a restriction to flow and the effective relief area was diminished.

In 1998, Stevenson [21] presented global results about the Q-Rhor flameless device which is now produced by REMBE. The Q-Rhor is a cylinder flameless device. Stevenson indicates an efficiency factor between 70 to $90 \%$, depending on the size of the device and the nature of the dust explosion filter.

Going and Chatrathi [22] published in 2003 test records obtained using a cylindrical flameless venting device, (FlamQuench II device) produced by FIKE. Three test chambers were used $(0.5$, 2 and $4 \mathrm{~m}^{3}$ ), several device diameters $(8,14,20,24$ and 36 inches) and three different dusts (cornstarch, anthraquinone and coal) in addition to propane gas. Efficiencies vary between 72 and $100 \%$. No relationship can be established between the efficiency coefficient and the process conditions: $\mathrm{P}_{\text {red }}, \mathrm{K}_{\mathrm{St}}$, device sizes, ... It can be noticed that there is a severe experimental dispersion of the results: for some tests in similar conditions, a difference in the Pred measurement up to $40 \%$ is reached.

Later, in 2013, Snoeys [23] claimed that a "representative" efficiency coefficient of box type version of the flameless venting device (Flamquench II Square) would amount to $60 \%$. In the same period of time, Holbrow [24] tested a box type flameless venting device produced by FIKE (possibly the same model as that presented by Snoeys, [23]) on 0.5 and $2 \mathrm{~m}^{3}$ vessels using two dusts with a similar $\mathrm{K}_{\mathrm{St}}$ coefficient but with very different particle size distributions: corn flour $\left(\mathrm{K}_{\mathrm{St}}=147 \mathrm{bar} . \mathrm{m} / \mathrm{s}, \quad 100 \%<63 \mu \mathrm{m}\right)$ and wheat flour $\left(\mathrm{K}_{\mathrm{St}}=138 \mathrm{bar} . \mathrm{m} / \mathrm{s}\right.$, PSD: $63 \mu \mathrm{m}<90 \%<180 \mu \mathrm{m})$. With wheat flour $\mathrm{P}_{\text {red }}$ with the flameless venting devices did not exceed those measured with the vent panels alone (thus implying an efficiency of the Flameless relatively to the vent of $100 \%$ ). With corn flour, $\mathrm{P}_{\text {red }}$ measured with the flameless venting devices are much larger than with the vent panels alone. These results were unexpected and pointed out that two organic flours of similar explosion parameters $\left(\mathrm{K}_{\mathrm{St}}, \mathrm{P}_{\max }\right)$ may nevertheless behave very differently as far as flameless venting is concerned.

Recently Chao and Dorofeev [25] proposed a methodology to calculate the overall efficiency of a flameless system by multiplying the efficiency coefficient of the venting device standing alone by an estimated efficiency of the dust explosion filter standing alone. Equations are proposed to estimate these parameters based on three different models from FM Global, NFPA 68 and VDI 3673. The equations take into consideration the usual parameters for the dusts and the vents such as the physical vent area or the $\mathrm{K}_{\mathrm{St}}$, but no specific attention is laid on the type of dust nor its concentration. Cornstarch dust was used at two different $\mathrm{K}_{\mathrm{St}}$ (adjusted varying the ignition delay) to simulate ST1 and ST2 dusts. The overall efficiency is found to be poorly dependent on the reactivity parameter as it is $77 \%$ for the ST1 case and $76 \%$ for the ST2 case. However, Chao points out a significant variability in the measurements for tests in the same conditions, which make the detailed interpretation of the results more complicated.

So many open questions remain, in particular on the interaction of the gas-particle flow with the porous mesh, that is poorly understood. An effect of granulometry and shape of the particles, as well as a concentration effect are expected, but still unquantified. Also, because Flameless devices efficiency is seemingly dependent on the test / process conditions, a practical model for Flameless vents dimensioning is needed. 


\section{Experiments on Flameless venting}

\subsection{Experimental details}

In the scope of the current paper, we are interested in BOX type Flameless devices. Four flameless venting devices from different, (and concurrent) producers were tested. In total 30 to 40 tests, on 3 different cylindrical explosion vessels of 1,10 and $21 \mathrm{~m}^{3}$ were performed (Table $1)$.

\begin{tabular}{|c|c|c|c|}
\hline Vessel volume & Length & Diameter & L/D ratio \\
\hline 1 & 1.5 & 0.92 & 1.6 \\
10 & 3.9 & 1.8 & 2.2 \\
21 & 6.5 & 2.1 & 3.1 \\
\hline
\end{tabular}

Table 1 Characteristic dimensions of the test vessels

The $1 \mathrm{~m}^{3}$ vessel is the standard ISO6184/1 vessel developed by Bartknecht [26], in which the mixture is ignited by $25 \mathrm{~kJ}$ igniters and the dust injection is performed within $600 \mathrm{~ms}$ with a 20 bar pressurized bottle of 51 , through a perforated tore. The $10 \mathrm{~m}^{3}$ and the $21 \mathrm{~m}^{3}$ vessel rely on different dust injection technologies.

In the $10 \mathrm{~m}^{3}$ vessel a fluidized particle bed is generated in a dedicated tank of 701 , to mix and deagglomerate the dust. After a $30 \mathrm{~s}$ fluidization phase the particle bed is injected into the vessel over $5 \mathrm{~s}$ through a DN32 pipe then ignited with $25 \mathrm{~kJ}$ igniters. Further details on this injection device may be found in [27].

Oppositely to the 1 and $10 \mathrm{~m}^{3}$ vessels that belong to the authors of this study, the $21 \mathrm{~m}^{3}$ vessel is that of the ATEX Gmbh company, located in Germany. In the $21 \mathrm{~m}^{3}$ vessel, the dust injection is performed from the radius of the vessel at 4 different locations evenly distributed, with 4201 bottles pressurized at 10 bar, through DN80 pipes. This aims at distributing the dust cloud along vessel, while most of the jets momentum is kept over the vessel diameter. The injection phase lasts from 200 to $300 \mathrm{~ms}$ and the dust is ignited later at $\mathrm{t}=600 \mathrm{~ms}$ with $25 \mathrm{~kJ}$ igniters.

Note that in practically all tests performed, the ignition location is set a one side of the vessel, opposite to the tested Flameless vent. The few exceptions with central ignition concern tests in the $10 \mathrm{~m}^{3}$ vessel, mentioned in section 3.3.3. Oppositely, dust $\mathrm{K}_{\mathrm{St}}$ and $\mathrm{P}_{\max }$ are measured with central ignition. A relevant information here for the 3 vessels is that during the process of dust injection, the mean longitudinal velocity of the dust cloud in the vessel is null: no dust jet is directed towards the vents/Flameless devices.

Different kinds of particles were tested: food-processing dusts (cornstarch, wheat flour, potato starch), Sulphur dust (to investigate the effect of low MIT-MIE), melting dusts (ice and crystal sugar), fibrous dust (wood flour) and metal dust (aluminum and Devarda aluminum alloy). The dust granulometry was measured for successful tests (Table 2) and when relevant, the dust concentration was varied. In some occurrences, the tested dust had to be mixed with a lower amount of the fine cornstarch dust to permit its correct dispersion and ignition. It is for example 
the case for the $21 \mathrm{~m}^{3}$ vessel tests with wheat flour in which the dust was mixed with $20 \%$ of cornstarch.

\begin{tabular}{|l|l|l|l|l|l|}
\hline Dust & $\mathrm{D}(\mathrm{v}, 0.1)(\mu \mathrm{m})$ & $\mathrm{D}(\mathrm{v}, 1 / 3)(\mu \mathrm{m})$ & $\mathrm{D}(\mathrm{v}, 0.5)(\mu \mathrm{m})$ & $\mathrm{D}(\mathrm{v}, 2 / 3)(\mu \mathrm{m})$ & $\mathrm{D}(\mathrm{v}, 0.9)(\mu \mathrm{m})$ \\
\hline Cornstarch & 10.6 & 17.5 & 24 & 30.9 & 51.2 \\
\hline Cristal sugar & 516 & 666 & 756 & 859 & 976 \\
\hline Devarda alloy & 9.45 & 19.5 & 25.2 & 31.1 & 44.8 \\
\hline Ice sugar & 21.2 & 35.3 & 40.1 & 51.8 & 76 \\
\hline Potato starch & 21.2 & 35.3 & 45.6 & 51.8 & 66.9 \\
\hline Wheat flour & 17.5 & 48.1 & 74.7 & 96.2 & 149.7 \\
\hline Wood flour & 16.7 & 38.1 & 53 & 86.9 & 168.2 \\
\hline
\end{tabular}

* $\mathrm{D}(\mathrm{v}, \mathrm{x})$ is the characteristic particle diameter such that $\mathrm{x} \%$ in volume of the sample is thinner.

Table 2: Particle size distributions for the dusts tested

As an illustration, a comparison of the cornstarch and the wheat flour particles seen by SEM with 700x magnification is shown in Figure 3:
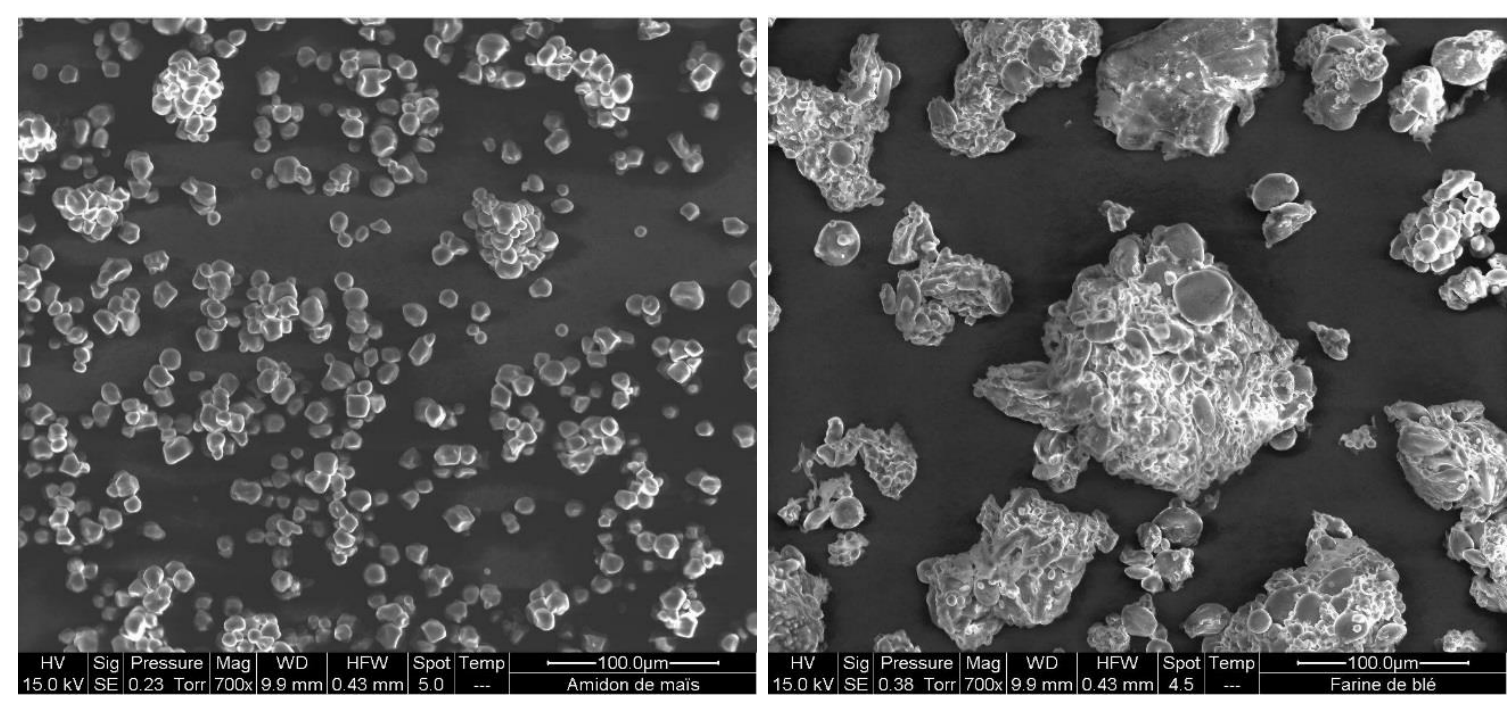

Figure 3 Cornstarch (left) vs. wheat flour particles (right) seen by a SEM at a 700x magnification

Not only the wheat-flour dust is coarser than the cornstarch dust, but it also forms larger agglomerates (which destruction at dust injection cannot be guaranteed). Given the fact that the flame may push significant amounts of fresh reactants ahead of its surface, such information and the data in Table 2, are to be put in contrast with the porous mesh characteristic holes dimensions.

The reactivity of the dusts was measured in the standard $1 \mathrm{~m}^{3}$ vessel, as described in EN140341 [27] and EN14034-2 [29] on the same vessel that is used for the vents and Flameless tests (Table 3). 


\begin{tabular}{|l|c|c|c|}
\hline \multicolumn{1}{|c|}{$\begin{array}{c}\text { Combustible } \\
-\end{array}$} & $\begin{array}{c}\text { Concentration } \\
\mathrm{g} / \mathrm{m}^{3}\end{array}$ & $\begin{array}{c}\mathrm{K}_{\mathrm{St}} \\
\text { bar.m/s }\end{array}$ & $\begin{array}{c}\mathrm{P}_{\max } \\
\text { bar }\end{array}$ \\
\hline Atomized aluminum $(10 \mu \mathrm{m})$ & 300 & 250 & 10.34 \\
Corn starch & 500 & 200 & 9,10 \\
Corn starch & 1000 & 200 & 9,85 \\
Cristal sugar (50\%) - cornstarch (50\%) & 500 & 100 & 8,65 \\
Cristal sugar (70\%) - cornstarch (30\%) & 1000 & 100 & 8,65 \\
Devarda aluminum alloy & 1000 & 60 & 7.20 \\
Ice sugar (70\%) - cornstarch (30\%) & 500 & 100 & 8,45 \\
Ice sugar (80\%) - cornstarch (20\%) & 1000 & 155 & 9,45 \\
Potato starch & 300 & 20 & 5,00 \\
Potato starch & 500 & 45 & 7,45 \\
Potato starch & 1000 & 90 & 9,00 \\
Sulphur & 500 & 155 & 7,55 \\
Wheat flour & 500 & 75 & 6,69 \\
Wheat flour & 1000 & 95 & 6,43 \\
Wood flour & 300 & 165 & 8,45 \\
Wood flour & 500 & 225 & 9,10 \\
\hline
\end{tabular}

Table 3: Dust reactivity parameters measured in the $1 \mathrm{~m} 3$ vessel.

Four types of flameless venting devices were tested, they consisted on box-types (BOX1, BOX2, BOX3 and BOX4. The experimental configurations are, summarized in Table 4to give a general overview. Each configuration is better described later in the document.

\begin{tabular}{|c|c|c|c|c|c|c|}
\hline $\begin{array}{c}\text { Flameless } \\
\text { device }\end{array}$ & Dust tested & $\begin{array}{c}\text { Ignition } \\
\text { location in } \\
\text { the vessel }\end{array}$ & $\begin{array}{c}\text { Vessel } \\
\text { volume } \\
\left(\mathrm{m}^{3}\right)\end{array}$ & $\begin{array}{c}\text { Dust } \\
\text { concentration } \\
\left(\mathrm{g} / \mathrm{m}^{3}\right)\end{array}$ & $\begin{array}{c}\text { Flameless } \\
\text { devices per } \\
\text { test }\end{array}$ & $\begin{array}{c}\text { Flameless } \\
\text { venting area } \\
\left(\mathrm{m}^{2}\right)\end{array}$ \\
\hline BOX1 & $\begin{array}{c}\text { All types } \\
\text { listed }\end{array}$ & $\begin{array}{c}\text { Back or } \\
\text { center }\end{array}$ & $\begin{array}{c}1,10 \text { and } \\
21\end{array}$ & $\begin{array}{c}300,500 \text { or } \\
1000\end{array}$ & 1 to 2 & $\begin{array}{c}7 \text { sizes } 0.079 \\
\text { to } 1.277 \mathrm{~m}^{2}\end{array}$ \\
BOX2 & Cornstarch & Back & 10 & 500 & 2 & $2 \times 0.539$ \\
BOX4 & $\begin{array}{c}\text { Wheat flour } \\
\text { Wheat flour } \\
\text { and cornstarch }\end{array}$ & Back & 10 & 1000 & 3 & 0.228 \\
\hline
\end{tabular}

Table 4: General summary of the experimental configurations investigated

In most cases 4 pressure gauges (Kistler piezoelectric gauges) were used: 2 inside the vessel (one at the back of the vessel, opposite to the Flameless device and close to the tested device), 1 on the dispersion system (to control the injection process), and 1 outside at $5 \mathrm{~m}$ in front of each vent (or flameless vent). In the $21 \mathrm{~m}^{3}$ vessel an additional pressure sensor located at the vessel center is used. Thermocouples were also used to control the temperature outside the vessel (on the pressure gauge and over the surface of the flameless device). A high-speed camera (Photron APX) was used (2000 frames per second in a 1024x1024 pixels window), and a standard HD camera. 


\subsection{Data reduction}

In a Flameless device, the gases are firstly unloaded from the vessel to the chamber, in which the pressure will rise, then from the chamber to the outside. As suggested by Chao [25], this double interface crossing may be described assuming a certain independency between the vent and the flameless mesh, each having its own efficiency. The overall efficiency of the system is the product of both efficiencies. Because the standard vent efficiency is not the object of current research, it has been decided to focus on the Flameless mesh by adopting a similar methodology as exposed by Chao.

A relative Flameless efficiency is considered, named "relative efficiency" or $E_{R}$. This relative efficiency must be multiplied by the vent efficiency to obtain the overall flameless efficiency. It is measured following an adaptation of the method of EN14797 [14] for assessing the vent efficiency, described in paragraph 2.3: a first test is performed with a vent panel alone, to determine the $\mathrm{P}_{\max } . \mathrm{K}_{\mathrm{St}}$ product value, assuming a vent efficiency of $100 \%$. Then the Flameless is tested and its relative efficiency $E_{R}$ is computed using the formulas of EN14491 [3] (equations 7 to 9). This offers the advantage to obtain a measurement that is quite independent from $\mathrm{P}_{\max } \cdot \mathrm{K}_{\mathrm{St}}$, provided the explosion of the reference vent test remains like that produced for the Flameless device. To ensure the validity this last point, for each case, the pressure records obtained with the vent and the flameless are superposed, to ensure the initial rate of pressure rise, before the vent opening, is the same.

\subsection{Results}

\subsubsection{BOX1}

The BOX1 system was tested on the 3 different volumes. It is a BOX type flameless: a vent opens in a chamber on which the filter covers an angle of $135^{\circ}$ over $180^{\circ}$ on the radial direction. No filtering elements are present on the sides of the chamber. The filter equipped with a particle retention grid, which smallest holes hydraulic diameter is close to $80 \mu \mathrm{m}$.

\subsection{2 $1 \mathrm{~m}^{3}$ vessel}

Most of the tests in the $1 \mathrm{~m}^{3}$ were carried out with $0.0799 \mathrm{~m}^{2}$ venting devices. A single configuration (test BOX1-12 in Table 5) was investigated with a larger device, with $0.175 \mathrm{~m}^{2}$ of physical vent area. Test data are summarized in Table 5: 


\begin{tabular}{|c|c|c|c|c|c|c|}
\hline Test & Dust & Concentration $\left(\mathrm{g} / \mathrm{m}^{3}\right)$ & $\mathrm{A}_{0}\left(\mathrm{~m}^{2}\right)$ & $\mathrm{P}_{\text {red,vent }}(\mathrm{bar})$ & $\mathrm{P}_{\text {red,flameless (bar) }}$ & $\mathrm{E}_{\mathrm{R}}(\%)$ \\
\hline BOX1-1 & wood flour & 300 & 0.0799 & 1.54 & 2.59 & 74 \\
\hline BOX1-2 & wood flour & 500 & 0.0799 & 1.58 & 3.57 & 63 \\
\hline BOX1-3 & Potato starch & 300 & 0.0799 & 0.15 & 0.19 & 83 \\
\hline BOX1-4 & Potato starch & 500 & 0.0799 & 0.21 & 0.39 & 59 \\
\hline BOX1-5 & Potato starch & 1000 & 0.0799 & 0.32 & 1.52 & 23 \\
\hline BOX1-6 & $\begin{array}{l}\text { Cristal sugar (50 } \\
\%) \text { Cornstarch } \\
(50 \%)\end{array}$ & 500 & 0.0799 & 0.55 & 0.95 & 60 \\
\hline BOX1-7 & $\begin{array}{c}\text { Cristal sugar (70 } \\
\%) \text { Cornstarch } \\
(30 \%)\end{array}$ & 1000 & 0.0799 & 0.72 & 1.13 & 65 \\
\hline BOX1-8 & $\begin{array}{l}\text { Ice sugar }(70 \%) \\
\text { Cornstarch }(30 \%)\end{array}$ & 500 & 0.0799 & 1.38 & 2.05 & 77 \\
\hline BOX1-9 & $\begin{array}{l}\text { Ice sugar }(80 \%) \\
\text { Cornstarch }(20 \%)\end{array}$ & 1000 & 0.0799 & 1.51 & 2.21 & 81 \\
\hline $\begin{array}{c}\text { BOX1- } \\
10\end{array}$ & Cornstarch & 500 & 0.0799 & 1.8 & 2.14 & 91 \\
\hline $\begin{array}{c}\text { BOX1- } \\
11\end{array}$ & Cornstarch & 1000 & 0.0799 & 1.32 & 2.12 & 72 \\
\hline $\begin{array}{l}\text { BOX1- } \\
12\end{array}$ & Devarda alloy & 1000 & 0.175 & 0.19 & 0.21 & 90 \\
\hline
\end{tabular}

Table 5: Tests performed with BOX1 flameless devices on the $1 m^{3}$ vessel.

Tests with ice and crystal sugar show a lower reproducibility, attributed to a difficult mixing of those dusts with cornstarch, to ease ignition. Furthermore, the crystal sugar dust is the coarsest (500 $\mu \mathrm{m}$ particles) and it is likely that a large part of these particles sediment before ignition. In any case the tests with sugars aimed to investigate the mesh clogging effect when melting dusts are used. It has been verified after each test that a significant amount of sticky material was present in the vessel. Besides the case of the sugars there is a clear evidence that dust concentration increases lead to lower relative efficiencies. Pressure measurements for the wood flour dust are provided thereafter as an illustration: 

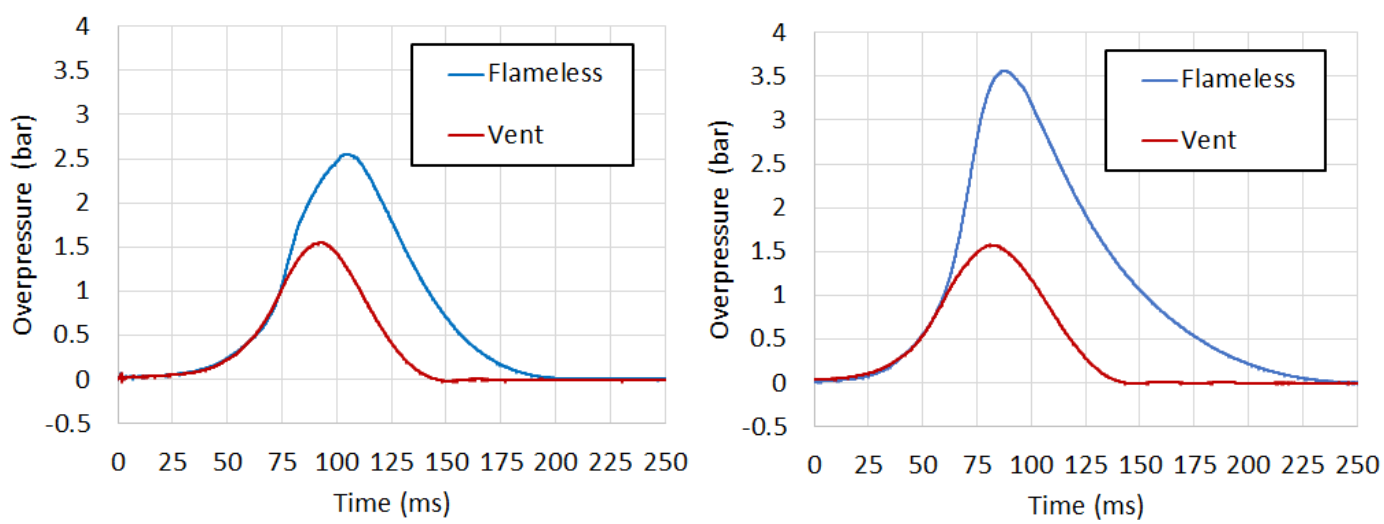

Figure 4 Comparison of pressure records obtained with a standard vent panel (red curves) and a Flameless device (blue curves) in the case of wood flour explosions in the $1 \mathrm{~m}^{3}$ vessel, at concentrations of $300 \mathrm{~g} / \mathrm{m} 3$ (left side) and $500 \mathrm{~g} / \mathrm{m} 3$ (right side)

With the larger dust concentration, the overpressure measured in the vessel is higher, but it is also interesting to look at the discharge rate which is also smaller. A comparison of the overpressures at $2 \mathrm{~m}$ from the vent show that there is barely any difference between the 2 cases despite the much higher overpressure obtained at the larger dust concentration. This observation is common to all of the tests performed and illustrates the progressive clogging of the mesh when dust concentration is increased (As a reminder: the vent and the Flameless mesh are replaced between each test).

Two configurations led to a failure of the flame quenching function (Table 6):

\begin{tabular}{|c|c|c|c|c|c|c|}
\hline Test & dust & concentration $\left(\mathrm{g} / \mathrm{m}^{3}\right)$ & $\mathrm{A}_{0}\left(\mathrm{~m}^{2}\right)$ & $\mathrm{P}_{\text {red,vent }}(\mathrm{bar})$ & $\mathrm{P}_{\text {red,flameless }}(\mathrm{bar})$ & $\mathrm{E}_{\mathrm{R}}(\%)$ \\
\hline BOX1-13 & Aluminum & 300 & 0.0799 & 0.589 & 2.95 & 27 \\
BOX1-14 & Sulphur & 500 & 0.0799 & 1.36 & 2.02 & 76 \\
\hline
\end{tabular}

Table 6: Tests performed with BOX1 flameless devices on the $1 \mathrm{~m}^{3}$ vessel with failure of the flame quenching function.

In these two tests, the venting function of the system was assured, but flames were seen outside in both cases. With aluminum, the flame temperature is much higher than with the other dusts (typically $3000 \mathrm{~K}$ versus $2000 \mathrm{~K}$ ), and the failure of the quenching function is most likely due to an insufficient cooling of the burning cloud by the mesh. Alternatively, in the sulfur case, the low minimum ignition temperature, of about $250{ }^{\circ} \mathrm{C}$, is believed to be responsible for the failure of the flame quenching. However, it is interesting to note that the device itself remained relatively cool, its surface temperature not exceeding $150{ }^{\circ} \mathrm{C}$. The same device was tested on the $10 \mathrm{~m}^{3}$ with organic dusts (cornstarch, wheat flour) and temperatures above $300{ }^{\circ} \mathrm{C}$ were measured on the mesh despite a successful venting, with lower $\mathrm{P}_{\text {red }}$ and no flame outside of the device. This implies that in the range of temperatures below usual dust auto-ignition temperatures $\left(\approx 400{ }^{\circ} \mathrm{C}\right)$, the Flameless mesh temperature gives no relevant information on its capability to quench a flame. 


\subsection{3 $10 \mathrm{~m}^{3}$ vessel}

In this vessel three sizes of the BOX1 device were investigated, with two different dusts, and three levels of concentration (Table 7). In some cases, two devices were used to vent the explosion. For tests 21 to 23, the ignition was performed at the center of the vessel.

\begin{tabular}{|c|c|c|c|c|c|c|c|c|}
\hline Test & Dust & $\begin{array}{c}\text { Conc. } \\
\left(\mathrm{g} / \mathrm{m}^{3}\right)\end{array}$ & $\begin{array}{c}\mathrm{K}_{\mathrm{St}} \\
(\mathrm{bar} . \mathrm{m} / \mathrm{s})\end{array}$ & $\begin{array}{c}\mathrm{P}_{\max } \\
(\mathrm{bar})\end{array}$ & $\mathrm{A}_{0}\left(\mathrm{~m}^{2}\right)$ & $\begin{array}{c}\mathrm{P}_{\text {red,vent }} \\
(\mathrm{bar})\end{array}$ & $\begin{array}{c}\mathrm{P}_{\text {red,flameless }} \\
(\mathrm{bar})\end{array}$ & $\mathrm{E}_{\mathrm{R}}(\%)$ \\
\hline BOX1-15 & Wheat flour & 500 & 100 & 8.00 & $2 \times 0.5391$ & 0.17 & 0.78 & 37 \\
BOX1-16 & Wheat flour & 1000 & 100 & 8.00 & $2 \times 0.5391$ & 0.17 & 1.28 & 27 \\
BOX1-17 & Cornstarch & 500 & 150 & 9.87 & $2 \times 0.5391$ & 0.18 & 0.34 & 67 \\
BOX1-18 & Cornstarch & 1000 & 150 & 9.87 & $2 \times 0.5391$ & 0.17 & 0.80 & 37 \\
BOX1-19 & Cornstarch & 500 & 74 & 7.00 & 0.5391 & 0.20 & 0.47 & 47 \\
BOX1-20 & Cornstarch & 1000 & 187 & 9.87 & 0.5391 & 0.80 & 2.35 & 39 \\
BOX1-21 & Cornstarch & 300 & 150 & 8.00 & 0.5391 & 0.49 & 0.56 & 91 \\
BOX1-22 & Cornstarch & 300 & 150 & 8.00 & 0.3721 & 0.85 & 0.94 & 94 \\
BOX1-23 & Cornstarch & $\mathbf{3 0 0}$ & $\mathbf{1 5 0}$ & $\mathbf{8 . 0 0}$ & $\mathbf{0 . 2 2 7 5}$ & $\mathbf{1 . 9 0}$ & $\mathbf{2 . 2 0}$ & $\mathbf{9 2}$ \\
\hline
\end{tabular}

Table 7: Tests performed with BOX1 flameless device on the $10 \mathrm{~m}^{3}$ vessel. Test 23 in bold indicate a failed quenching of the flame

Table 7 shows a poor efficiency of the wheat flour dust in comparison to the cornstarch dust despite its lower reactivity. This goes against the standard venting models (see equation 8 , in which lower $\mathrm{K}_{\mathrm{St}}$ implies lower vent areas). Again, the effect of concentration is very noticeable. All other parameters being equal, the larger the amount of dust in the vessel, the lower is the efficiency (test 15-16 or 17-18). With wheat flour the efficiency is much lower: tests 15 and 18 led to similar $\mathrm{P}_{\text {red, }}$, despite half of the mass of particles was used in the case of the wheat flour (Figure 5).

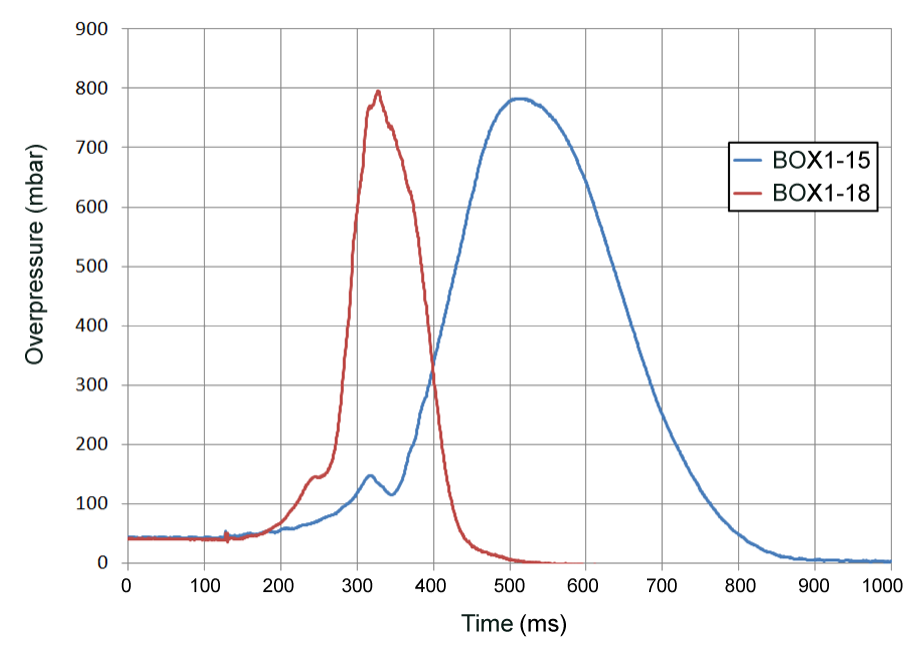

Figure 5 Pressure records for tests BOX1-15 and BOXI-18 (respectively $500 \mathrm{~g} / \mathrm{m}^{3}$ of wheat flour and $1000 \mathrm{~g} / \mathrm{m}^{3}$ of cornstarch in the $10 \mathrm{~m}^{3}$ vessel)

As expected, the pressure rise is much slower for wheat flour (blue curve in Figure 5 but the same value for $\mathrm{P}_{\text {red }}$ is reached. This can be understood considering the depressurization phase 
(after $\mathrm{P}_{\text {red }}$. The discharge of the vessel is driven by the pressure difference between the inside of the vessel and the outside of the flameless device and by the effective free area through the filter. The faster pressure decay rate in test 4 for the cornstarch explosion reveals the effective free area is larger than during the wheat flour explosion. So, wheat flour particles tend to clog more rapidly than cornstarch. It was noticed that the smaller mesh cell of the tested devices is $80 \mu \mathrm{m}$ large. Considering Table 2, it is clear that a significant proportion (may be 50\%) of the wheat flour particles will not go through whereas most of the cornstarch particle will.

Table 7 also demonstrate that depending on the test conditions the same device may show an excellent efficiency or oppositely a very bad one. At last in test 23 , despite an excellent venting efficiency the system failed to quench the flame and got heated at temperatures above $600{ }^{\circ} \mathrm{C}$. This shows that the 2 conditions for efficient flameless venting: the venting capability of the system to protect the enclosure and the ability to isolate the enclosure (so that no flame can be transmitted to the outside area) may not be correlated.

\subsection{4 $21 \mathrm{~m}^{3}$ vessel}

3 configurations were investigated on this scale, there were 2 successful tests with cornstarch particles and a failed test with wheat flour, in which the Flameless device did not withstand the high $\mathrm{P}_{\text {red }}$ value.

\begin{tabular}{|c|c|c|c|c|c|c|c|c|}
\hline Test & Dust & $\begin{array}{c}\text { Conc. } \\
\left(\mathrm{g} / \mathrm{m}^{3}\right)\end{array}$ & $\begin{array}{c}\mathrm{K}_{\mathrm{St}} \\
(\text { bar.m/s) }\end{array}$ & $\begin{array}{c}\mathrm{P}_{\max } \\
(\text { bar })\end{array}$ & $\mathrm{A}_{0}\left(\mathrm{~m}^{2}\right)$ & $\begin{array}{c}\mathrm{P}_{\text {red,vent }} \\
(\text { bar })\end{array}$ & $\begin{array}{c}\mathrm{P}_{\text {red,flameless }} \\
(\text { bar })\end{array}$ & $\mathrm{E}_{\mathrm{R}}(\%)$ \\
\hline BOX1-24 & Cornstarch & 1000 & 150 & 9.00 & 1.2769 & 0.53 & 1.80 & 25 \\
BOX1-25 & Cornstarch & 300 & 170 & 8.00 & 0.8464 & 0.85 & 2.00 & 29 \\
BOX1-26 & Wheat flour & $\mathbf{1 0 0 0}$ & $\mathbf{7 0}$ & $\mathbf{7 . 0 0}$ & $\mathbf{1 . 2 7 6 9}$ & $\mathbf{0 . 1 8}$ & $\mathbf{2 . 8 9}$ & $\mathbf{0}$ \\
\hline
\end{tabular}

Table 8 Tests performed with BOX1 flameless device on the $21 \mathrm{~m}^{3}$ vessel. Test 26 in bold indicate a failed test, with ejection of the Flameless device

In those tests, large amounts of dust are used, and the Flameless relative efficiencies are poorer. Again, the mesh clogging by the particles can explain the strong differences between the vent alone case and the Flameless test. Photographs of the inside of the Flameless were taken after a test with cornstarch (Figure 6):
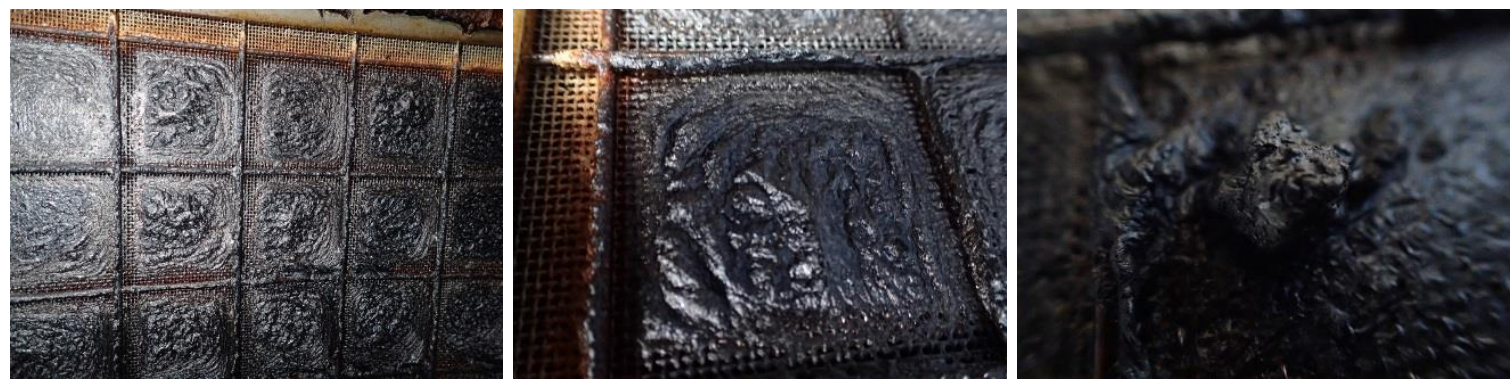

Figure 6 Inside of the $1130 \times 1130 \mathrm{~mm}$ Flameless device after test BOX1-24 with $1000 \mathrm{~g} / \mathrm{m}^{3}$ of cornstarch. 
In the case of wheat flour the mesh was sufficiently obstructed to allow reaching an overpressure close to 3 bar which led to its destruction. An efficiency can be estimated only looking at the measured $\mathrm{P}_{\text {red }}$ and omitting the device was ejected, which leads to the result of $7 \%$. It would have been even lower if the system would have withstood the explosion.

\subsubsection{BOX2}

The BOX2 prototype is a modified version of the BOX1 system in which only the filter was changed. This filter did not contain any particle retention screen, so that the smallest holes in the mesh have a hydraulic diameter on the order of $0.5 \mathrm{~mm}$ in spite of $80 \mu \mathrm{m}$ for BOX1. It was tested in same conditions as in test BOX1-17. The results are compared in Table 9

\begin{tabular}{|c|c|c|c|c|c|c|c|c|}
\hline Test & Dust & $\begin{array}{c}\text { Conc. } \\
\left(\mathrm{g} / \mathrm{m}^{3}\right)\end{array}$ & $\begin{array}{c}\mathrm{K}_{\mathrm{St}} \\
(\mathrm{bar} . \mathrm{m} / \mathrm{s})\end{array}$ & $\begin{array}{c}\mathrm{P}_{\max } \\
(\mathrm{bar})\end{array}$ & $\mathrm{A}_{0}\left(\mathrm{~m}^{2}\right)$ & $\begin{array}{c}\mathrm{P}_{\text {red,vent }} \\
(\text { bar })\end{array}$ & $\begin{array}{c}\mathrm{P}_{\text {red,flameless }} \\
(\mathrm{bar})\end{array}$ & $\mathrm{E}_{\mathrm{R}}(\%)$ \\
\hline BOX2-1 & Cornstarch & 500 & 150 & 9.87 & $2 \times 0.5391$ & 0.18 & 0.20 & 94 \\
BOX1-17 & Cornstarch & 500 & 150 & 9.87 & $2 \times 0.5391$ & 0.18 & 0.34 & 67 \\
\hline
\end{tabular}

Table 9: Tests performed with BOX2 flameless device.

Both tests are compared with the reference vent test in Figure 7:

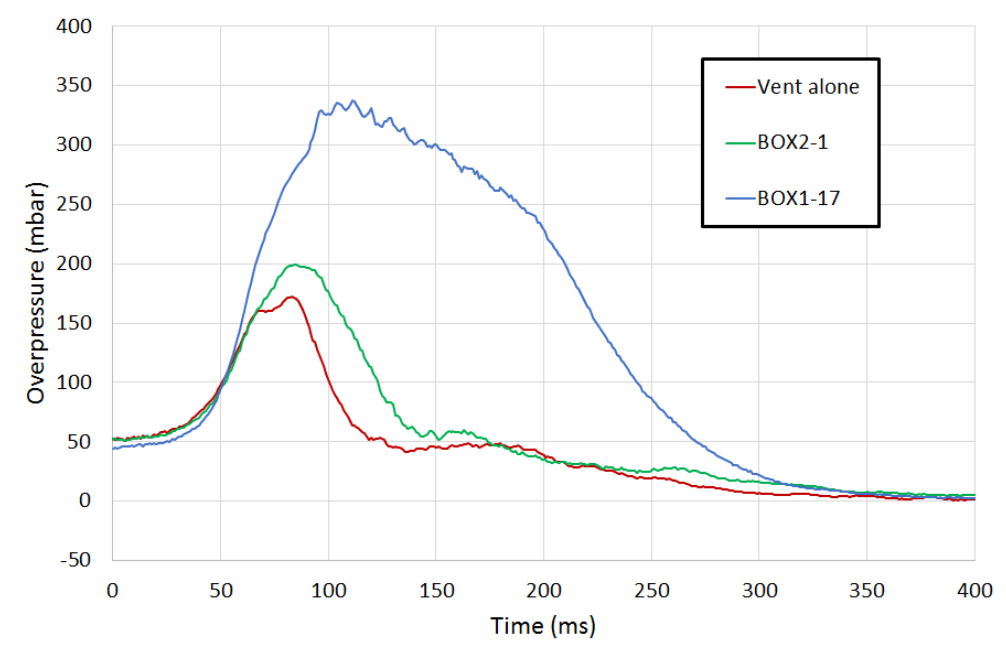

Figure 7 BOX2-1 and BOX1-17 pressure records compared with the standard vent case. $500 \mathrm{~g} / \mathrm{m}^{3}$ of cornstarch, same flameless devices but different filters

The initial rates of pressure rises are similar testifying the same kind of explosion. However, the pressure discharge is much more efficient for BOX2. Alternatively, the observation of video records for those tests reveals that a much denser cloud of unburnt material is visible outside the vessel in the case of the BOX2 device. It is more efficient in terms of venting, in these specific conditions, but it is likely to generate an explosible cloud outside of the protected enclosure.

\subsection{6 $\quad$ BOX3}

BOX3 Flameless device is still a BOX type Flameless device as presented earlier but its technology is different from that of the BOX1 or BOX2. It was tested a single time. During this 
test, 3 Flameless vents of a relatively small dimension $(350 \times 650 \mathrm{~mm})$ were used on the $10 \mathrm{~m}^{3}$ vessel. No information was obtained on the minimal mesh dimension, but to our experience, the mesh was very similar to that of BOX1, including a particle retention screen. It covers an angle from 0 to $90^{\circ}$ in the chamber. A complete failure of the flameless vents was observed, despite a relatively low dust reactivity. The dust was ignited at the center of the vessel in this case.

\begin{tabular}{|c|c|c|c|c|c|c|c|c|}
\hline Test & Dust & $\begin{array}{c}\text { Conc. } \\
\left(\mathrm{g} / \mathrm{m}^{3}\right)\end{array}$ & $\begin{array}{c}\mathrm{K}_{\mathrm{St}} \\
(\text { bar.m/s })\end{array}$ & $\begin{array}{c}\mathrm{P}_{\max } \\
(\mathrm{bar})\end{array}$ & $\mathrm{A}_{0}\left(\mathrm{~m}^{2}\right)$ & $\begin{array}{c}\mathrm{P}_{\text {red,vent }} \\
(\text { bar })\end{array}$ & $\begin{array}{c}\mathrm{P}_{\text {red,flameless }} \\
(\text { bar })\end{array}$ & $\mathrm{E}_{\mathrm{R}}(\%)$ \\
\hline BOX3-1 & Wheat flour & 700 & 95 & 8.00 & $3 \times 0.2275$ & 0.14 & 1.6 & 0 \\
\hline
\end{tabular}

Table 10: Tests performed with BOX3 flameless device.

If the devices did resist the explosion, their efficiency would not have been larger than $15 \%$ (calculation based on the measured $\mathrm{P}_{\mathrm{red}}$ ). Interestingly, the same device was tested successfully on another test site. But these experiments were performed using additional standard vent panels on the explosion chamber (of about $3 \mathrm{~m}^{3}$ ) whereas at no additional vent was used in our study. Presumably the testing conditions have an influence. When an additional vent is used a large proportion of the dust cloud goes directly outside without flowing through the dust explosion filter so that the clogging effect is significantly reduced. This is a major finding as it can lead to dramatic misinterpretation of the performances of the system.

\subsection{7 $\quad$ BOX4}

Again, BOX4 is an entirely different device from those described previously. It was tested in the $10 \mathrm{~m}^{3}$ vessel with wheat flour. This device includes a particle retention screen which hydraulic diameter is on the order of 50-100 $\mu \mathrm{m}$, covering an angle from 0 to $130^{\circ}$ in the radial direction after the vent. In this case, the vent in the Flameless device has a $P_{\text {stat }}$ of 200 mbar $\left(\mathrm{P}_{\text {stat }}=100 \mathrm{mbar}\right.$ in all of the other cases). Aside this standard efficiency evaluation (one reference test with a vent and one with the Flameless device), an additional test (test BOX4-2) was performed. The Flameless device was not reconditioned and no vent (membrane) was used inside of it. The device was tested in similar conditions as BOX4-1 to estimate the consequence of the clogging (Table 11).

\begin{tabular}{|c|c|c|c|c|c|c|c|c|}
\hline Test & Dust & $\begin{array}{c}\text { Conc. } \\
\left(\mathrm{g} / \mathrm{m}^{3}\right)\end{array}$ & $\begin{array}{c}\mathrm{K}_{\mathrm{St}} \\
(\mathrm{bar} . \mathrm{m} / \mathrm{s})\end{array}$ & $\begin{array}{c}\mathrm{P}_{\max } \\
(\mathrm{bar})\end{array}$ & $\begin{array}{c}\mathrm{A}_{0} \\
\left(\mathrm{~m}^{2}\right)\end{array}$ & $\begin{array}{c}\mathrm{P}_{\text {red, vent }} \\
(\mathrm{bar})\end{array}$ & $\begin{array}{c}\mathrm{P}_{\text {red,flameless }} \\
(\mathrm{bar})\end{array}$ & $\mathrm{E}_{\mathrm{R}}(\%)$ \\
\hline BOX4-1 & $\begin{array}{c}\text { Wheat } \\
\text { flour }\end{array}$ & 700 & 112 & 9.50 & 1.21 & 0.56 & 1.61 & 35 \\
\hline $\begin{array}{c}\text { BOX4-2 } \\
\text { Not reconditioned }\end{array}$ & $\begin{array}{c}\text { Wheat } \\
\text { flour }\end{array}$ & $\mathbf{7 0 0}$ & $\mathbf{1 1 2}$ & $\mathbf{9 . 5 0}$ & $\mathbf{1 . 2 1}$ & - & $\mathbf{1 . 9 4}$ & $\mathbf{0}$ \\
\hline
\end{tabular}

Table 11: Tests performed with BOX4 flameless device. For the test in bold, there was no vent in the Flameless device (no reconditioned since the earlier test), and the device was ejected.

As there was no vent (no membrane) in tests BOX4-2, only the filter is tested and despite the absence of a vent the $\mathrm{P}_{\text {red }}$ was not only higher, but it also led to the complete failure of the device which was ripped off in two large pieces ejected at 20 and $25 \mathrm{~m}$. 


\section{Discussion}

Present data are in line with published information. For instance, the presence of the filter on the flameless is able to retain dusts, quench the flames but alters the flow and lead to higher $\mathrm{P}_{\text {red }}$ and lower efficiency coefficients.

Additionally, some of these results underlined some specific points:

- the filter restrains the flow and has a significant effect on the explosion discharge,

- large amounts of particles do block the flameless filters during the discharge,

- an even partially blocked filter may allow extreme pressure build-up in the vessel, even when the dust explosion is weak,

- $\quad$ and perhaps the most important: adding a standard vent on the same explosion vessel as that on which the flameless device is placed, may completely changes the flow in an uncontrolled manner and can lead to dramatic misinterpretation of the performances of the flameless venting device.

This demonstrates that the present physical mechanisms are more complicated than a simple discharge of a pressurized volume of gas throughout a porous media. The two following aspects need to be considered:

1) The "filtering" effect of the flameless device: solid particles are expected to seal a part of the holes in the flameless filter, slowing down the flow in this system.

2) The extra gas volume produced by the combustion (as compared to normal venting): most of the particles remain trapped inside the chamber all along the discharge process which constitutes a large difference as compared to normal venting. The burning or pyrolysis of those particles would produce extra volume of gases and maintain a rather high level of pressure. The decrease of the pressure should occur when the flame would have propagated throughout the whole volume or the vessel and extinguished.

A direct consequence of this is that the flameless device may not behave as a vent, especially when large dust loads are concerned, and the vent dimensioning rules may not be applied without due consideration. For instance, large concentrations of weakly reactive powders (thus low $\mathrm{K}_{\mathrm{St}}$ values) may lead to hazardous situations whenever a flameless device were to be used. Particles will be stuck in the grids and limit the discharge surface of the flameless device while the rest of the burning particles will generate significant pressure rise at a later time, which would lead to an uncontrolled pressure rise in the tank. Consequently, when the dust concentration reaches a certain level the flameless system may not behave as standard vents anymore, this is a critical parameter of the system. Admittedly, estimating the dust concentration in an industrial process in accidental conditions is a challenging task and only a limited number of flameless producers mention concentration limits for their systems.

Is it possible to account for those phenomena? Experiments showed that a same device (BOX1), may exhibit 3 regimes of functioning in terms of venting capabilities:

1) a complete failure, with ripping off the device, occurring when the relative efficiency is lower than $25 \%$ (lowest value measured for a positive test) 
2) a vent like behavior with efficiencies on the order of $90 \%$,

3) an intermediate regime with very variable efficiency between 25 and $90 \%$.

Thus, to obtain a predictive model, the first step is to define a parameter that can indicate in which regime the explosion venting takes place. This parameter will be noted $\mathrm{P}_{\mathrm{G}}$. Clearly, the limiting phenomenon is the flow of burning mixture through the flameless device, inducing a clogging effect. This suggests a need to estimate the amount of unburnt dust that will penetrate the mesh during the explosion. If a spherical flame expansion is assumed in a cubic closed vessel of side dimension $\mathrm{D}$, then one can tell that at the time when the flame touches the walls the burnt fraction is relatively small:

$$
\frac{\text { Burnt mass }}{\text { Initial mass }}=\frac{\rho_{b} \cdot \frac{4}{3} \cdot \pi \cdot \frac{D^{3}}{8}}{\rho_{f} \cdot D^{3}}=\frac{\rho_{b}}{\rho_{f}} \cdot \frac{\pi}{6} \approx 10 \%
$$

with $\rho_{b}$ and $\rho_{\mathrm{f}}$ the densities of the burnt products and the reactants, which ratio should be on the order of 5 at the minimum. The vessels are not cubes but cylinders with L/D ratios between 1.6 and 3.1. Because the quantity of burnt dust should remain relatively small by the time the flame reaches the vent, a conservative approach is chosen considering that all the dust can be pushed by the flame, into the mesh.

Furthermore, some parameters of the enclosure can be intuitively considered as relevant in the process of dust pushing through the mesh, such as the total volume $\mathrm{V}$ and the maximal flame length up to the vent in the enclosure $\mathrm{L}_{\mathrm{f}}$. An increase of these parameters for a same Flameless device and a fixed density of reactants is expected to worsen the particle clogging. Also, for the same total mass of dust, having a wider vent area is expected to be of some help. A schematic can be helpful to understand how these parameters can intervene in the venting process (Figure $8)$.

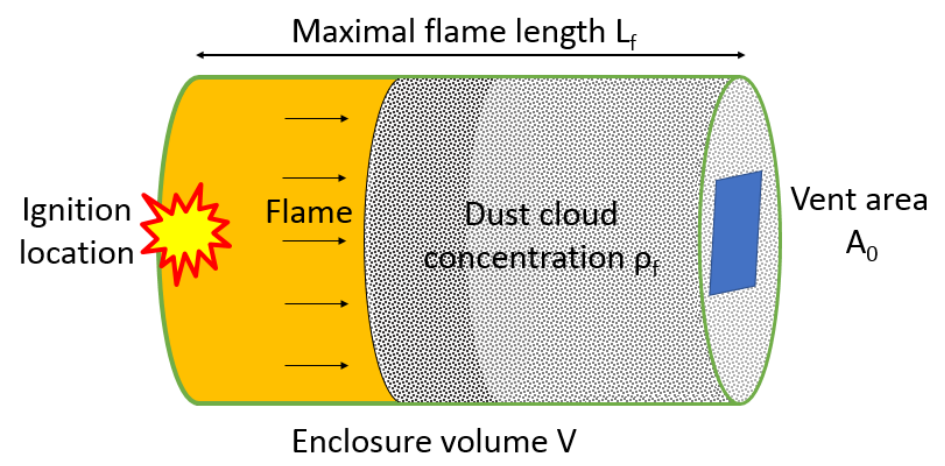

Figure 8 Schematic of the dust pushing phenomena

At last, the result must depend on the dust specific nature: metallic, fibrous, melting ... This feature is much more difficult to account for as it cannot be quantified through a simple variable. These considerations are taken in account in the definition of the clogging parameter $\mathrm{P}_{\mathrm{G}}$, it takes the form of equation 11:

$$
P_{G}=C \cdot \frac{A_{0}^{a}}{V^{b} \cdot L_{f}^{c} \cdot \rho_{f}^{d}}
$$


The densities of the reactants $\rho_{\mathrm{f}}$ integrates the air density plus the dust concentration in the volume $\mathrm{V}$. The exponents $\mathrm{a}, \mathrm{b}, \mathrm{c}$ and $\mathrm{d}$ are expected to be positive numbers and $\mathrm{C}$ is a coefficient to grant the homogeneity of the equation. The terms at the numerator play a positive role in solving the clogging problem while those in the denominator have an adverse effect. Then, depending on the dust nature, different correlations are expected to be found. To determine a, $\mathrm{b}, \mathrm{c}, \mathrm{d}$ and $\mathrm{C}$ in equation 11, we rely on the test data available. At first, the case of the BOX1 tests with cornstarch and a single Flameless device is used to find an experimental fit. We find: $\mathrm{a}=4 / 3 ; \mathrm{b}=2 / 3 ; \mathrm{c}=2 ; \mathrm{d}=2$ and $\mathrm{C}=320 \mathrm{~kg}^{2} \cdot \mathrm{m}^{-14 / 3}$. The value of $\mathrm{C}=320 \mathrm{~kg}^{2} \cdot \mathrm{m}^{-14 / 3}$ is chosen so that $\mathrm{P}_{\mathrm{G}}=$ at the turning region between the intermediate region and the vent-like regime.

The $\mathrm{P}_{\mathrm{G}}$ equation becomes:

which can also be written as:

$$
P_{G}=320 \cdot \frac{A_{0}^{4 / 3}}{V^{2 / 3} \cdot L_{f}^{2} \cdot \rho_{f}^{2}}
$$

$$
P_{G}=320 \cdot \frac{A_{0}}{V^{2 / 3}} \cdot\left(\frac{1}{L_{f} \cdot \rho_{f}}\right)^{2} \cdot A_{0}^{1 / 3}
$$

in which the $A_{0} / V^{2 / 3}$ factor can also be recognized in the usual venting equations presented in paragraph 2.2. The $P_{G}$ term also shows a strong dependence, in square, to the inverse of the surface reactants density (flame length times density). This underlines the major incidence of the dust concentration and flame length on the venting capabilities of a given device.

Finally, a linear correlation for $\mathrm{E}_{\mathrm{R}}$ and $\mathrm{P}_{\mathrm{G}}$ can be expressed as:

$$
\begin{gathered}
E_{R}=90 . P_{G} \\
25 \% \leq E_{R} \leq 90 \%
\end{gathered}
$$

It is specifically interesting to remark that the model also seems to coincide with published results with a satisfying accuracy (Table 12 and Figure 9):

\begin{tabular}{|c|c|l|l|l|l|l|c|c|}
\hline Test & $\begin{array}{c}\text { Conc. } \\
\left(\mathrm{kg} / \mathrm{m}^{3}\right)\end{array}$ & Lf $(\mathrm{m})$ & $\mathrm{V}\left(\mathrm{m}^{3}\right)$ & $\mathrm{A}_{0}\left(\mathrm{~m}^{2}\right)$ & $\mathrm{P}_{\mathrm{G}}$ & $\begin{array}{c}\mathrm{E}_{\mathrm{R}} \text { tests } \\
(\%)\end{array}$ & $\begin{array}{c}\mathrm{E}_{\mathrm{R}} \\
\text { model } \\
(\%)\end{array}$ & $\begin{array}{c}\text { Error } \\
\text { (points) }\end{array}$ \\
\hline BOX1-10 & 500 & 1.65 & 1.1 & 0.0799 & 1.30 & 91 & 90 & 1 \\
BOX1-11 & 1000 & 1.65 & 1.1 & 0.0799 & 0.78 & 72 & 70 & 2 \\
BOX1-19 & 500 & 3.90 & 10.0 & 0.5391 & 0.66 & 61 & 62 & 1 \\
BOX1-20 & 1000 & 3.90 & 10.0 & 0.5391 & 0.40 & 39 & 36 & 3 \\
BOX1-21 & 300 & 1.95 & 10.0 & 0.5391 & 3.41 & 91 & 90 & 1 \\
BOX1-22 & 300 & 1.95 & 10.0 & 0.3721 & 1.12 & 92 & 90 & 4 \\
BOX1-23 & 300 & 1.95 & 10.0 & 0.2275 & 2.16 & 94 & 90 & 2 \\
BOX1-24 & 1000 & 6.50 & 21.0 & 1.2769 & 0.28 & 25 & 26 & 0 \\
BOX1-25 & 300 & 6.50 & 21.0 & 0.8464 & 0.35 & 29 & 32 & 3 \\
\hline Chao et al. (ST1) & 750 & 2.90 & 8.0 & 0.4400 & 0.84 & 77 & 75 & 2 \\
Chao et al. (ST2) & 750 & 2.90 & 8.0 & 0.4400 & 0.84 & 76 & 75 & 1 \\
\hline
\end{tabular}




\begin{tabular}{|c|c|l|l|l|l|l|c|c|}
\hline Test & $\begin{array}{c}\text { Conc. } \\
\left(\mathrm{kg} / \mathrm{m}^{3}\right)\end{array}$ & $\mathrm{Lf}(\mathrm{m})$ & $\mathrm{V}\left(\mathrm{m}^{3}\right)$ & $\mathrm{A}_{0}\left(\mathrm{~m}^{2}\right)$ & $\mathrm{P}_{\mathrm{G}}$ & $\begin{array}{c}\mathrm{E}_{\mathrm{R}} \text { tests } \\
(\%)\end{array}$ & $\begin{array}{c}\mathrm{E}_{\mathrm{R}} \\
\text { model } \\
(\%)\end{array}$ & $\begin{array}{c}\text { Error } \\
\text { (points) }\end{array}$ \\
\hline Going et al. & 500 & 0.49 & 0.5 & 0.0324 & 1.87 & 101 & 90 & 11 \\
Going et al. & 500 & 0.49 & 0.5 & 0.0993 & 8.34 & 81 & 90 & 9 \\
Going et al. & 750 & 0.49 & 0.5 & 0.0993 & 6.34 & 93 & 90 & 3 \\
Going et al. & 500 & 0.49 & 0.5 & 0.0993 & 8.34 & 93 & 90 & 3 \\
Going et al. & 50 & 0.78 & 2.0 & 0.0993 & 2.43 & 97 & 90 & 7 \\
Going et al. & 500 & 0.78 & 2.0 & 0.0993 & 1.31 & 91 & 90 & 1 \\
Going et al. & 500 & 0.78 & 2.0 & 0.2027 & 3.40 & 74 & 90 & 16 \\
Going et al. & 500 & 0.78 & 2.0 & 0.2027 & 3.40 & 101 & 90 & 11 \\
Going et al. & 500 & 0.78 & 2.0 & 0.2919 & 5.53 & 108 & 90 & 18 \\
Going et al. & 500 & 0.78 & 2.0 & 0.2919 & 5.53 & 74 & 90 & 16 \\
Going et al. & 500 & 0.78 & 2.0 & 0.2919 & 5.53 & 82 & 90 & 8 \\
Going et al. & 500 & 1.05 & 4.0 & 0.6567 & 5.72 & 81 & 90 & 9 \\
\hline
\end{tabular}

Table 12: Application of the model to all the available experimental data on flameless venting of cornstarch explosions with a single device. The last column is the absolute difference between the measured efficiency and that predicted with the model.

Note that this model also works with test BOX1-23 in which the flame quenching failed. Again, ensuring the venting function does not guarantees the flameless function, even when the efficiency is as high as $\mathbf{9 0 \%}$.

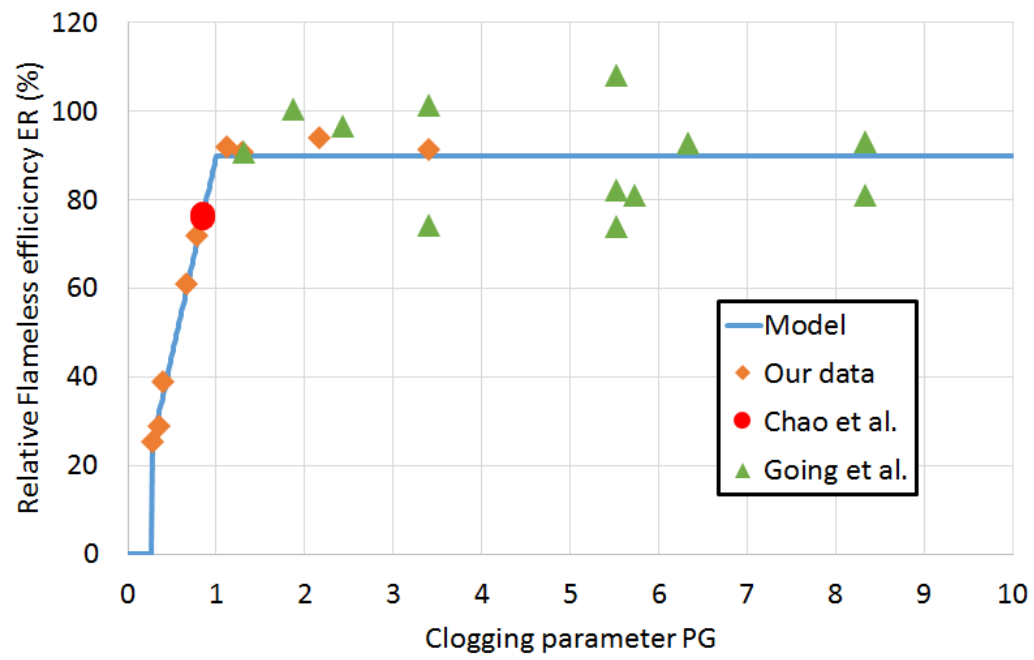

Figure 9 Comparison of the model with all the available experimental data on flameless venting of cornstarch explosions with a single device.

The three regimes of functioning of the flameless vent are clearly shown in such graphic: below a $P_{G}$ value of 0.28 , the efficiency of the device is not proven (as destruction of the device was observed below this value) and set to 0 . Above 1 , relatively low amounts of dust are pushed 
through the mesh and it practically behave has a vent but with a flow restriction due to head losses. Note that despite a wider spreading of the points, the data published by Going [22] is in line with the model predictions. In the intermediate area, the model can represent the significant variations of $E_{R}$ with an excellent accuracy, even for the data published by Chao [25]. The former might however be a coincidence as one would expect that different Flameless devices, would have different mesh dimensions thus different clogging sensitivities, leading to variations of the coefficients in equation 14. The trends should be conserved but a wider dataset is necessary to shed light on this specific aspect.

The next issue to address is the case of the other particles. From our tests two categories were found: the case of the coarsest particles, of wheat flour, and the case of the intermediate size particles with the potato starch or the fibrous wood flour. The equations for the two cases are given thereafter:

$$
\begin{aligned}
\text { Intermediate particles : } & E_{R}=61 . P_{G}-22 \\
\text { Wheat flour } & E_{R}=15 . P_{G}+12 \\
25 \% \leq E_{R} \leq 90 \% &
\end{aligned}
$$

A graphical representation is provided in Figure 10. Unfortunately, literature data is still lacking for dusts other than cornstarch. Going et al. [22] tested coal and anthraquinone but the results published present a lower interest in the present case, as they concern values of $\mathrm{P}_{\mathrm{G}}$ larger than 1.8 with efficiencies larger than $90 \%$ (which is consistent with the model but provides limited information for a potential validation in the intermediate region).

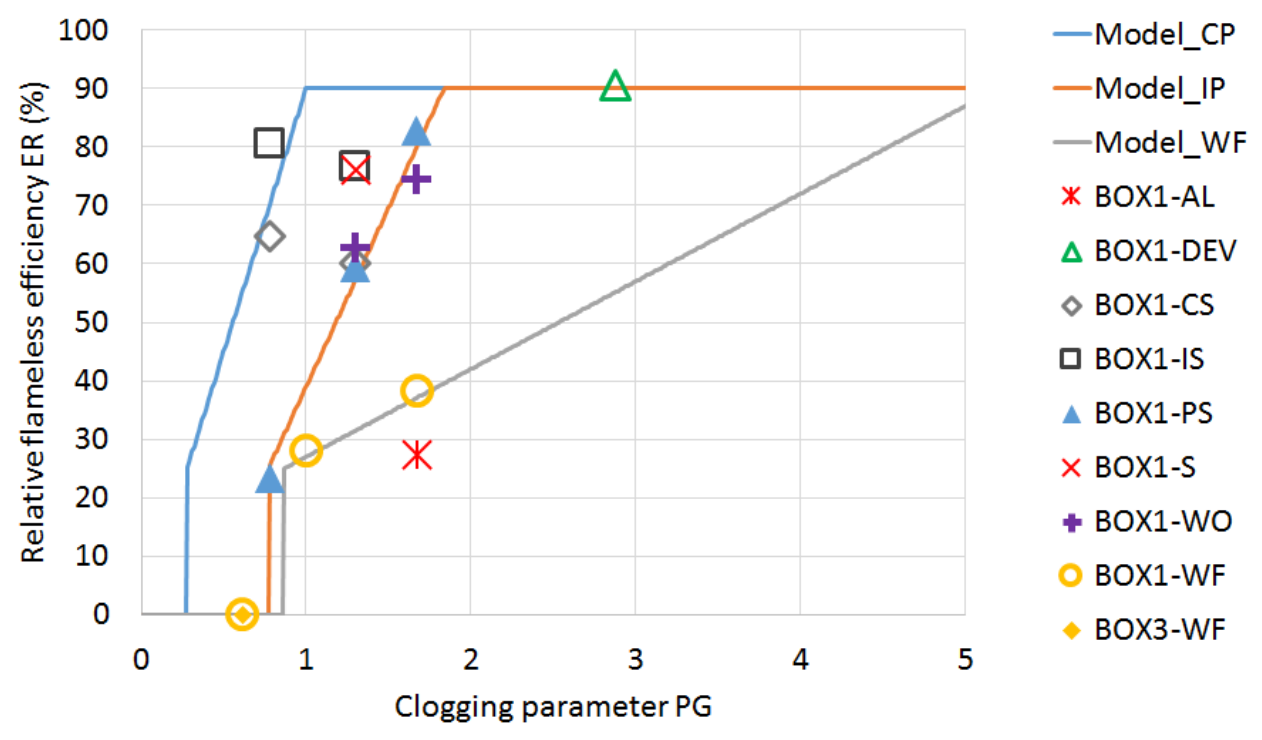

Figure 10 Application of the models for dusts other than cornstarch. Acronyms: CP: cornstarch particles; IP: intermediate particles; WF: wheat flour; AL: aluminum; DEV: Devarda alloy;

CS: crystal sugar; IS: ice sugar; PS: potato starch; S: Sulphur; WO: wood flour.

There is a good agreement between the measured relative efficiencies (marks) and those computed by the different models (straight lines). The agreement is preserved when devices other than the BOX1 flameless vent are considered. A few discrepancies are identified. First, the ice and crystal sugars show variable behavior, in-between the model for cornstarch (finer) dust and the intermediate particles one. This can be explained by the fact that the sugars had to be mixed with cornstarch to allow the generation reproducible explosions. Then, the sulphur 
and the aluminum particles tests are out of all models' predictions. However, in these two configurations, a flame passed through the filter, so the discrepancy might be due to a change in the flow conditions downstream the mesh. In the case of the Devarda alloy, the result fits with 2 of the models but we still lack experimental data to tell whether it would actually comply with any of these models in the intermediate efficiency range or not.

So, how does it apply to vent dimensioning in an industrial application? A small hindrance of the model can be noticed: it uses the physical vent area $\mathrm{A}_{0}$ as an entry parameter. This implies an iterative calculation:

1. first the needed physical vent area $A_{0}$ must be estimated with usual venting equations knowing the process conditions (V, Kst, Pmax, ...)

2. a flameless of vent area $A_{v}>A_{0}$ is chosen accordingly: it comprises a vent of known efficiency $E v$ and a mesh of efficiency $E_{R}$, to be determined. Thus, $A_{0}=A_{V} /\left(E_{V} * E_{R}\right)$

3. knowing the dust type, and concentration, one can select a proper relative efficiency model for the relative Flameless efficiency $E_{R}$. In the example of cornstarch, equations 13 and 14 lead to:

$$
E_{R}=\left(288 \cdot \frac{\left(\frac{A_{V}}{E_{V}}\right)^{4 / 3}}{V^{2 / 3} \cdot L_{f}^{2} \cdot \rho_{f}^{2}}\right)^{3 / 7}
$$

$$
25 \% \leq E_{R} \leq 90 \%
$$

4. Then, if $E_{R}$ is below $25 \%$, the venting area is not sufficient, and a larger device must be selected (and the calculation goes back to step 2). In the other case, the value of $E_{R}$ can be used to dimension the venting solution. The $90 \%$ limit corresponds to the maximum efficiency reached by the device in the vent-like regime. It may vary with the device considered.

It appears that the presented model based on the determination of the $\mathrm{P}_{\mathrm{G}}$ parameter can be used for dimensioning flameless venting solution, provided certain precautions are considered, such as well defining the flame length, dust nature/morphology and concentration. Those results concern box type flameless, but what can be said concerning the disk types and cylinder types presented in section 2? Based on our experiences, a significant influence of the mesh on the discharge is expected: in the specific situation of the BOX2 device, the change of the mesh led to a significant gain in efficiency. The issue of the absence of a particle retention filter put aside, this means that the available mesh area plays a significant role in the venting process. A direct consequence is that devices with larger mesh area over vent area ratios are expected to show better efficiency. In other words, for comparable dimensions a cylinder type flameless is expected to be more efficient than a box type one. We also had the opportunity to test disk type Flameless, but they are excluded from the present report as they are in fact based on an entirely different technology. The disc type device investigated consisted in a spring valve connected to the chamber which radial surface consisted in a superposition of thin steel disks through which the explosion can be vented. In practice, there is no particle retention screen and the relative efficiency of the device increases with the overpressure, possibly because the filtering elements are mobile. However, the device is said to be reusable (which could be justified by the absence 
of a particle retention screen in it), but our experiments showed that the efficiency was drastically decreased between two consecutive tests at medium levels of dust concentration (cornstarch at $500 \mathrm{~g} / \mathrm{m}^{3}$ )

Note finally that this discussion on the venting efficiency is independent from flame quenching capabilities of the Flameless device. To model such phenomenon, it is necessary to have enough information on the explosion conditions such as the volume of gases passing through the mesh, their temperature, the mesh mass, in view of estimating the heat exchange between the exploding material and the mesh. However, it is very likely that this calculation can be done only if the venting performance of the device is known. In practice, the European standard EN16009 imposes limitations that should guarantee the flame quenching function: a single Flameless device of a given dimension can be used only on an enclosure which volume does not exceed the maximum tested volume in the certification process for the same device. Furthermore, the dust cannot be of lower MIT/MIE or higher $\mathrm{P}_{\max }, \mathrm{K}_{\mathrm{ST}}$ or of a too different nature/morphology (metal dusts, melting dusts, fibrous dusts, ...) in comparison to the certification tests. This ensures that the effects of the explosion in the industrial application in which the device is used are weaker than those investigated during the certification procedure.

\section{Conclusions}

The major result of this study is that the flameless device does not behave as a standard vent. Besides the problem of the unloading of the explosion in the tank, there is a highly complicated fluid mechanics problem of a fluid-particle flow passing through a porous media (the flameless device grids arrangement in the filter), which passing surface is progressively reduced. To characterize Flameless venting the problem can be addressed sequentially, considering separately the vent panel and the flameless mesh. Each part can be characterized by an efficiency coefficient, the overall final efficiency being the product of both. A semi-empirical model was proposed to estimate the relative efficiency, it is based on the determination of a clogging parameter noted $\mathrm{P}_{\mathrm{G}}$. The determination of $\mathrm{P}_{\mathrm{G}}$ is based on the usually available and demanded data when dimensioning venting applications, in addition to an information on dust nature and concentration. Over the range of data acquired in tests and found in the literature, the model shows satisfying predictive capabilities. It points out a dependence of the flameless efficiency with the square for the maximum flame length and density of the reactants, underlining the importance of the clogging effect due to the particles. Also, no dependence of the flameless efficiency with the dust reactivity was identified. A few difficulties are nonetheless identified. First, it needs the knowledge of minimal information on the dust nature or morphology. For example, coarser dusts will tend to clog the filter faster than fine powders. When several devices are used to protect the same vessel, the determination of the flame length and vent surface to consider still poses some challenges as too few experimental data are available. Also, when standard vent panels are used in conjunction with Flameless devices on the same enclosure, the relative efficiency of the Flameless is better yet unknown and not predictable with the current model. A small hindrance of the model: it uses the physical vent area $\mathrm{A}_{0}$ as an entry parameter, leading to iterative calculation of the mitigation solution, that are prone to errors. Also, it is necessary to always check that the relative efficiency remains above $25 \%$, because if it is not the case, a complete clogging and failure of the system is possible. This limit could however be due to the specificities of the devices tested. At last, it must be kept in mind that solving the venting issue is a necessary feature, but it is not sufficient to guarantee the flame quenching. The limit in volume stated in the device certificate is required 
to ensure the flame quenching condition. However, if the final venting efficiency is known, a phenomenological approach could be envisioned to develop a model for the flow through the flameless and estimate the heat absorption by the mesh, thus giving its capability to quench a flame in specific applications.

\section{Acknowledgements}

The devices investigated in the current paper were tested in the scope of their ATEX certification, for private companies. In particular, the authors wish to thank the STIF company, who provided a significant part of the material tested and accepted the unconditional publication of these test results.

\section{References}

[1] Roux P., 2000, Rapport Final. Guide pour la conception et l'exploitation, de silos de stockage de produits agro- alimentaires vis-à-vis des risques d'explosion et d'incendie. Ministère de l'Aménagement du territoire et de l'Environnement, freely available at www.ineris.fr

[2] VDI3673, 2002, Pressure Venting of Dust Explosions. Verein Deutscher Ingenieure, Dusseldorf, Germany.

[3] EN14491, 2012, Dust explosion venting protective systems, Published and distributed by Association Française de Normalisation (AFNOR — French standard institute). www.afnor.org

[4] NFPA 68, 2018, Standard on Explosion Protection by Deflagration Venting. National Fire Protection Association, Quincy, USA.

[5] EN16009, 2011, Flameless Explosion Venting Devices. Published and distributed by Association Française de Normalisation (AFNOR — French standard institute). www.afnor.org

[6] Proust, C., 1996, Dust explosions in pipes: a review. Journal of loss prevention in the process industries 9, 267-277.

[7] Lewis B., Von Elbe G., 1987, Combustion, flames and explosions of gases: 3rd edition, Academic Press, London, ISBN 0-12-446751-2

[8] Eckhoff R.K., 2003. Dust explosions in the process industries, 3. ed. ed. Gulf Professional Publ, Amsterdam.

[9] Proust C., Roux P., Chuuon B., 2000, "Prévoir les effets des explosions de poussières sur l'environnement EFFEX un outil de simulation", Rapport final d'une étude réalisée pour le compte du ministère de l'Environnement, freely available at www.ineris.fr

[10] Proust C., 2005, The usefulness of phenomenological tools to simulate the consequences of dust explosions : the experience of EFFEX, International ESMG Symposium on Process Safety and Industrial Explosion Protection, Nürnberg, Germany

[11] Tamanini, F., Valiulis, J.V., 1996. Improved guidelines for the sizing of vents in dust explosions. Journal of Loss Prevention in the Process Industries 9, 105-118. https://doi.org/10.1016/0950-4230(95)00053-4 
[12] Zalosh, R., 2008. Firexplo Explosion Venting Data and Modeling Literature Review. Prepared for Fire Protection Research Foundataion 1 Batterymarch Park Quincy, MA 02169-7471.

[13] Daubech J., Leprette E., Duclos A., Proust C., 2018, “Accounting for turbulence in gas explosion venting design”, proceeding, ISHPMIE, Kansas City, USA

[14] EN14797 (2007), Explosion venting devices, Published and distributed by Association Française de Normalisation (AFNOR — French standard institute). www.afnor.org

[15] Alfert, F., and K.Fuhre, 1989, Flame and Dust Free Venting of Dust Explosions by Means of a Quenching Pipe, CMI Report No. 89 258201, Chr. Michelsen Institute(Norway)

[16] Holbrow P., 2006, Explosion protection using flameless venting - a review. Health and Safety Laboratory Report No. EC/05/50 October 2006 - Explosion Safety Unit HSL - Harpur Hill Buxton Derbyshire

[17] Barton J. ,2002, Dust explosion prevention and protection a practical guide, Institution of Chemical Engineers, Rugby, U. K \& Gulf Professional Publishing, ButterworthHeinemann, USA.

[18] STUVEX website : http://www.stuvex.com

[19] IEP technologies website : https://www.ieptechnologies.com

[20] Bartknecht, W. and Vogl, A. (1994). Flameless pressure relief and dust explosions, Staub. Reinhaltung der Luft, vol. 54, no3, 119-123.

[21] Stevenson, J.W. (1998). Dust explosion mitigation using Q-Rohr and Exkop. Process Saf. Prog. 17, 184-189.

[22] Going, J. E. and Chatrathi, K. (2003). Efficiency of flameless venting devices. Process Safety Progress; Vol. 22, No. 1.

[23] Snoeys, J., Going, J.E., and Taveau, J.R. (2013). Dust explosion protection by flameless venting, Chemical Engineering Transactions, 31, 733-738.

[24] Holbrow, P. (2013). Dust explosion venting of small vessels and flameless venting. Process Saf. Environ. Prot. 91, 183-190.

[25] Chao, J and Dorofeev S. B. (2015), Evaluating the overall efficiency of a flameless venting device for dust explosions, Journal of Loss Prevention in the Process Industries 36 (2015) 63-71.

[26] "ISO 6184/1", 1985, Explosion Protection Systems - Part 1: Determination of Explosion Indices of Combustible Dusts in Air, ISO 6184/1

[27] Y. Grégoire, C. Proust, E. Leprette, D. Jamois, 2017, Monitoring of a dust explosion in a $10 \mathrm{~m} 3$ vessel, 26th International Colloquium on the Dynamics of Explosions and Reactive Systems, Boston, USA

[28] EN14034-1+A1, 2011, Determination of explosion characteristics of dust clouds Part 1: Determination of the maximum explosion pressure Pmax of dust clouds, Published and distributed by Association Française de Normalisation (AFNOR — French standard institute). www.afnor.org

[29] EN14034-2+A1, 2011, Determination of explosion characteristics of dust clouds Part 2: Determination of the maximum rate of explosion pressure rise $(\mathrm{dp} / \mathrm{dt}) \mathrm{max}$ of dust clouds Published and distributed by Association Française de Normalisation (AFNOR — French standard institute). www.afnor.org 